
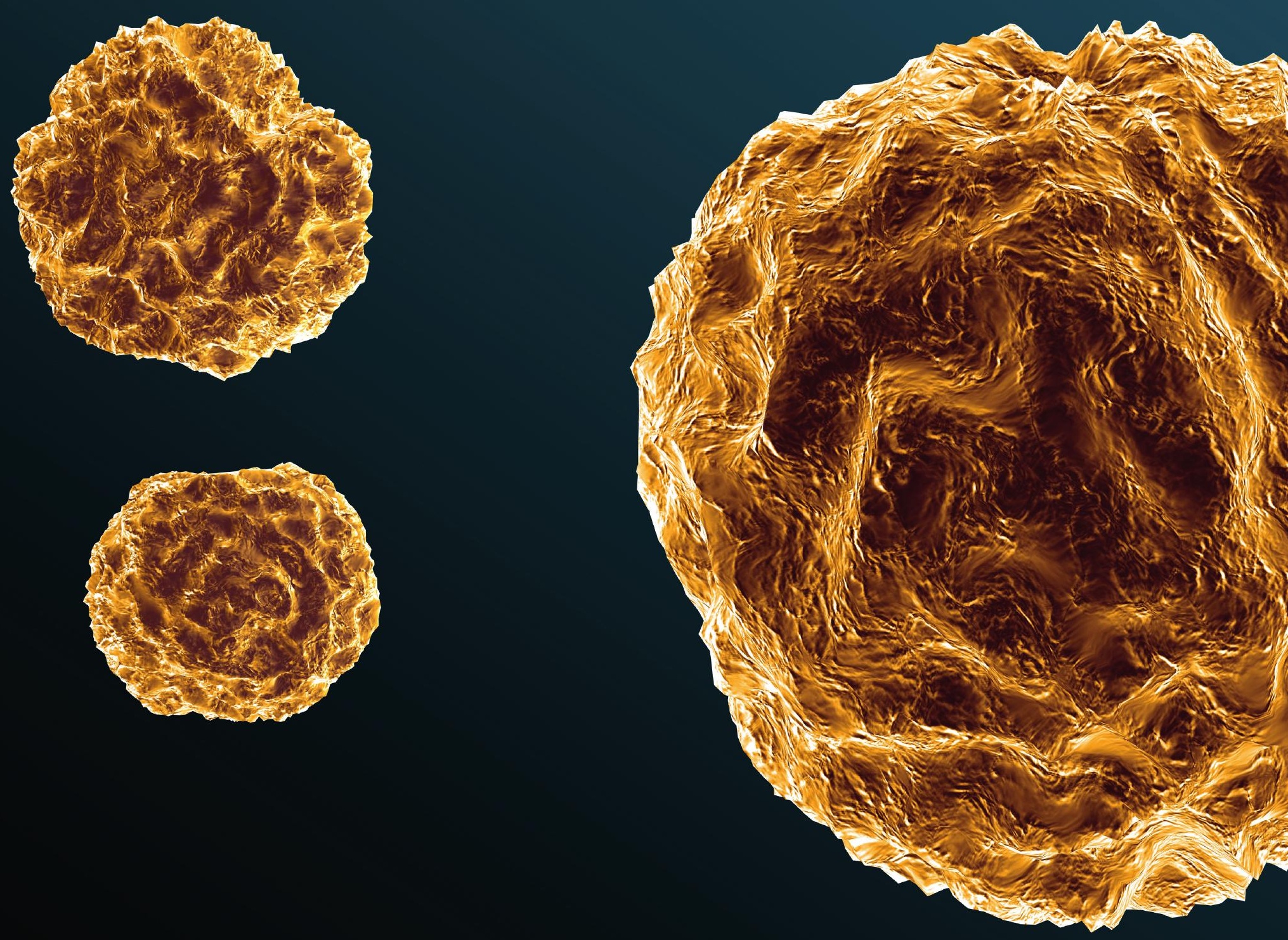

\title{
NIRS and manure composition (NIMACO)
}





\section{NIRS and manure composition (NIMACO)}

P.J.L. Derikx, B. van de Kooi, H. Heskamp and M. Rozijn

This research has been carried out as public-private collaboration project by Wageningen Food Safety Research, an institute within the legal entity Wageningen Research Foundation in close collaboration with private companies and has been subsidised by Topsector Kennis \& Innovatie (TKI) Agri \& Food and Tuinbouw \& Uitgangsmaterialen. 
Derikx, P.J.L., van de Kooi, B., Heskamp. H. and Rozijn, M., 2021. NIRS and manure composition (NIMACO). Wageningen, Wageningen Food Safety Research, WFSR report 2021.012. 48 pp.; 12 fig.; 5 tab.; 11 ref.

Project number: 1207386601

Project title: NIRS and manure composition (NIMACO)

Project leader: P.J.L. Derikx

This report can be downloaded for free at https://doi.org/10.18174/549611 or at www.wur.eu/foodsafety-research (under WFSR publications).

(C) 2021 Wageningen Food Safety Research, institute within the legal entity Wageningen Research Foundation. Hereinafter referred to as WFSR.

The client is allowed to publish or distribute the full report to third parties. Without prior written permission from WFSR it is not allowed to:

a) publish parts of this report;

b) use this report or title of this report in conducting legal procedures, for advertising, acquisition or other commercial purposes;

c) use the name of WFSR other than as the author of this report.

P.O. Box 230, 6700 AE Wageningen, The Netherlands, T +31 (0)317 4802 56, E info.wfsr@wur.nl, www.wur.eu/food-safety-research. WFSR is part of Wageningen University \& Research.

This report from WFSR has been produced with the utmost care. However, WFSR does not accept liability for any claims based on the contents of this report.

WFSR report 2021.012

Distribution list:

- J. Noordsij, LNV

- W. van Eck, TKI

- E. Muntinga, RVO

- P. Suijker, NVWA 


\section{Contents}

Preface $\quad 5$

$\begin{array}{ll}\text { Summary } & 7\end{array}$

1

$\begin{array}{ll}\text { Introduction } & 9\end{array}$

1.1 General introduction 9

1.2 Developments in on-site fertiliser analysis 10

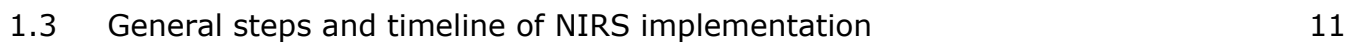

$\begin{array}{lll}1.4 & \text { Research within NIMACO } & 12\end{array}$

$\begin{array}{llr}2 & \text { NIMACO partners } & 13\end{array}$

$\begin{array}{llr}3 & \text { Methods } & 14\end{array}$

3.1 Proof of Principle 14

3.1.1 The POP protocol 14

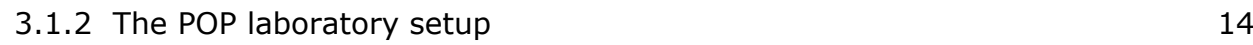

3.1.3 Composition of the slurry samples $\quad 15$

$\begin{array}{ll}3.1 .4 & \text { POP measurements } \\ & 15\end{array}$

3.1.5 Evaluation POP measurements 16

3.2 Proof of Application $\quad 16$

3.2.1 The POA approach 16

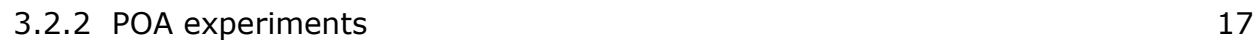

3.2.3 Evaluation POA measurements 18

3.3 Comparison of NIRS and conventional Sampling and Analysis 19

3.3.1 The principle of the comparison study 19

3.3.2 Preparation for the comparison study 20

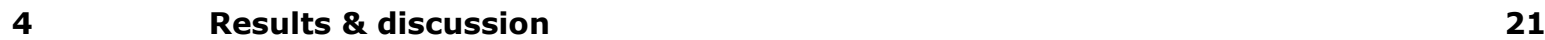

4.1 Proof of Principle $\quad 21$

4.2 Proof of Application $\quad 22$

$5 \quad$ Conclusion \& recommendations $\quad 26$

$\begin{array}{ll}\text { References } & \mathbf{2 7}\end{array}$

$\begin{array}{lll}\text { Annex } 1 & \text { Infographic on the application of NIRS } & 28\end{array}$

$\begin{array}{lll}\text { Annex } 2 & \text { POP protocol } & 29\end{array}$

$\begin{array}{lll}\text { Annex } 3 & \text { POP data evaluation } & 35\end{array}$

$\begin{array}{lll}\text { Annex } 4 & \text { POA protocol } & \mathbf{4 1}\end{array}$ 



\section{Preface}

WFSR annually conducts thousands of analyses to support NVWA (Dutch Food and Consumer Good Safety Authority) in its task to enforce any legal obligation dealing with food, feed and consumer good safety. To act pro-active in this field scientific research and development are crucial. For this reason, WFSR seeks participation in Public Private Cooperation research projects closely linked to food safety aspects in a broad sense. Environment responsible use of nutrients present in animal slurries is key for long term soil fertility and to protect deeper ground water as a safe source for our drinking water. With the development of online measuring techniques to evaluate the nutrient content of animal slurries, new instruments arise to make steps forward in closing nutrient cycles in agri-food production. WFSR endorses such developments and hopes this development fulfils its potential effect. 


\section{Summary}

Due to the gradual increase of intensive livestock farming in the Netherlands, the amount of nutrients in animal manure exceeds the demand for nutrients on arable land at the national level. In order to account for total amounts of nutrient inputs and outputs on farm level by manure, sampling and laboratory analysis is nowadays a major instrument within the Dutch Fertilizer Law. The major disadvantage of the system the delay between sampling during transport and the moment the laboratory results about the manure composition become available.

In recent decades miniaturized techniques, such as Near-Infrared Spectroscopy (NIRS) have become available to perform in situ fertiliser analysis, allowing direct availability of the measurement. The use of these techniques instead of the current system of sampling and analysis could solve the issue related to the time gap between sampling and the availability of the results and enables more precise application of slurry based on actual nutrient content. Over the past decade research has been performed to evaluate NIRS as a potential technique. In close collaboration with all parties involved, the Ministry of Agriculture designed a strategy for the gradual introduction of on board NIRS measurements at slurry transport vehicles for the determination of the total nitrogen and phosphorus content. This plan foresees an improvement of accuracy of NIRS systems over time to eventually meet the performance requirements of the fertilizer legislation.

The aim of the NIMACO research project was to gather more information from scientific based research on the performance of NIRS systems for the estimating nutrient content in animal slurry. More specifically for the application of NIRS on board of transport vehicles, estimating the nitrogen (N) and phosphorus (expressed as $\mathrm{P}_{2} \mathrm{O}_{5}$ ) content.

For this purpose, two protocols were established for the performance assessment of the NIRS systems. One to perform a Proof of Principle (POP), to evaluate the performance of the NIRS systems under laboratory conditions and one to perform a Proof of Application (POA), to evaluate the performance of the NIRS systems under field conditions. Furthermore, preparations were made to perform a comparison study where NIRS will be applied to monitor slurry data related to commercial transports that are carried out in the conventional way. The research on the latter topic will be addressed in a separate project directly following the NIMACO project. The performance of NIRS systems from three different manufactures have been evaluated according the POP. To date, the results of these tests do not show that the equipment has the accuracy deemed necessary to start a pilot where NIRS is used for the legal determination of the nitrogen and phosphorus content of slurry. Nonetheless, the observed accuracy of the equipment did increase over time by adjustments made by the suppliers to improve the systems. 


\section{Introduction}

\section{$1.1 \quad$ General introduction}

For centuries animal excrements have been a valuable source of nutrients used to fertilize arable and grass lands, closely linking animal husbandry with arable farming. In the second half of the last century the introduction of mineral fertilizers gradually uncoupled these two agriculture activities. Intensive animal production developed side by side with the import of huge amounts of cheap feed ingredients from all over the world. Consequently, the amount of nutrients originating from animal manure exceeds the demand of nutrients by arable farmers on a national level (1). Therefore, export of nutrients in manure derived products has been stimulated over the last decades. To prevent local over application additional legislation is put into force, resulting in manure being transported from concentrated livestock regions in the country to areas with arable land.

In order to account for total amounts of nutrient inputs and outputs on farm level, sampling and laboratory analysis is nowadays a major instrument within the Dutch Fertilizer Law. So far, the Dutch Fertilizer Law does not pose restrictions to the distribution of nutrient on individual fields. Each truck load of animal manure exchanging from owner has to be sampled and the sample is analysed by an AP05 (2) certified laboratory for determination of total phosphorous (expressed in $\mathrm{P}_{2} \mathrm{O}_{5}$ ) and total nitrogen $(\mathrm{N}$ ) content.

In the current situation manure is transported from regions with high livestock density towards regions with more arable land. The total volume of manure delivered on an individual farm depends on a rough estimate using average figures on nutrient content. Only after days/weeks the precisely known figures of $\mathrm{N}$ and $\mathrm{P}_{2} \mathrm{O}_{5}$ content become available. At that time most likely the slurry has already been applied on the farmland. To avoid any penalty for overapplication farmers with arable land stay on the safe side when it comes to accepting an additional truck load. In case the nutrient content of the manure remains below the expected value, the arable farmer can supply additional nutrients by using artificial fertiliser. Both in terms of operational costs and nutrient use efficiency from renewable resources this is an undesirable situation. Furthermore, in case the nutrient content of the animal slurry strongly exceeds the expected value, it results in overapplication for which the farmer will receive a fine and additional risks for water pollution.

In recent decades sophisticated measurement techniques like Near-Infrared Spectroscopy (NIRS) have been developed from voluminous and sensible laboratory equipment towards miniaturized and more solid-state based devices. NIRS applications in more harsh environments like inline production process control have been developed. Even for dusty and vibrating environments like on harvest machines applications have been introduced on the market to monitor yield and nutritional value of feed and food crops from harvesting to consumption. In addition, it has also led to commercially available NIRS systems that can be used on board of slurry application vehicles for more precise application of slurry based on the nutrient content ( $\mathrm{kg} \mathrm{N} / \mathrm{ha}$ instead of $\mathrm{m}^{3} / \mathrm{ha}$ ) (3).

The application of NIRS to determine the $\mathrm{N}$ and $\mathrm{P}_{2} \mathrm{O}_{5}$ concentrations allows for direct online availability of the nutrient content of the slurry transported, for all parties involved, as shown in Figure 1 . This potentially solves the problems described above related to the moment at which results are known. Furthermore, NIRS technology mounted on application vehicles combined with site-specific data opens the possibility for precision farming taking into account the nutrient availability of the soil and the crop nutrient uptake and demand during the complete growing season at field or subfield (zone) level.

One of the major challenges for the implementation of NIRS as an instrument to be used for the nutrient bookkeeping is to meet the accuracy requirements that are nowadays set for sampling and analysis (4). A competence of NIRS that greatly contributes to achieve the required accuracy, is that NIRS can be used to perform a continuous measurement over the complete time needed to load the trailer. While the current system of sampling analysis is based on the collection of only $5-9$ subsamples over the 
complete time of loading, followed by the subsequent analyses of the combined sample. The large number of measurements decreases the influence of the random measuring error and therefore, increases the accuracy of the average result at transport level.

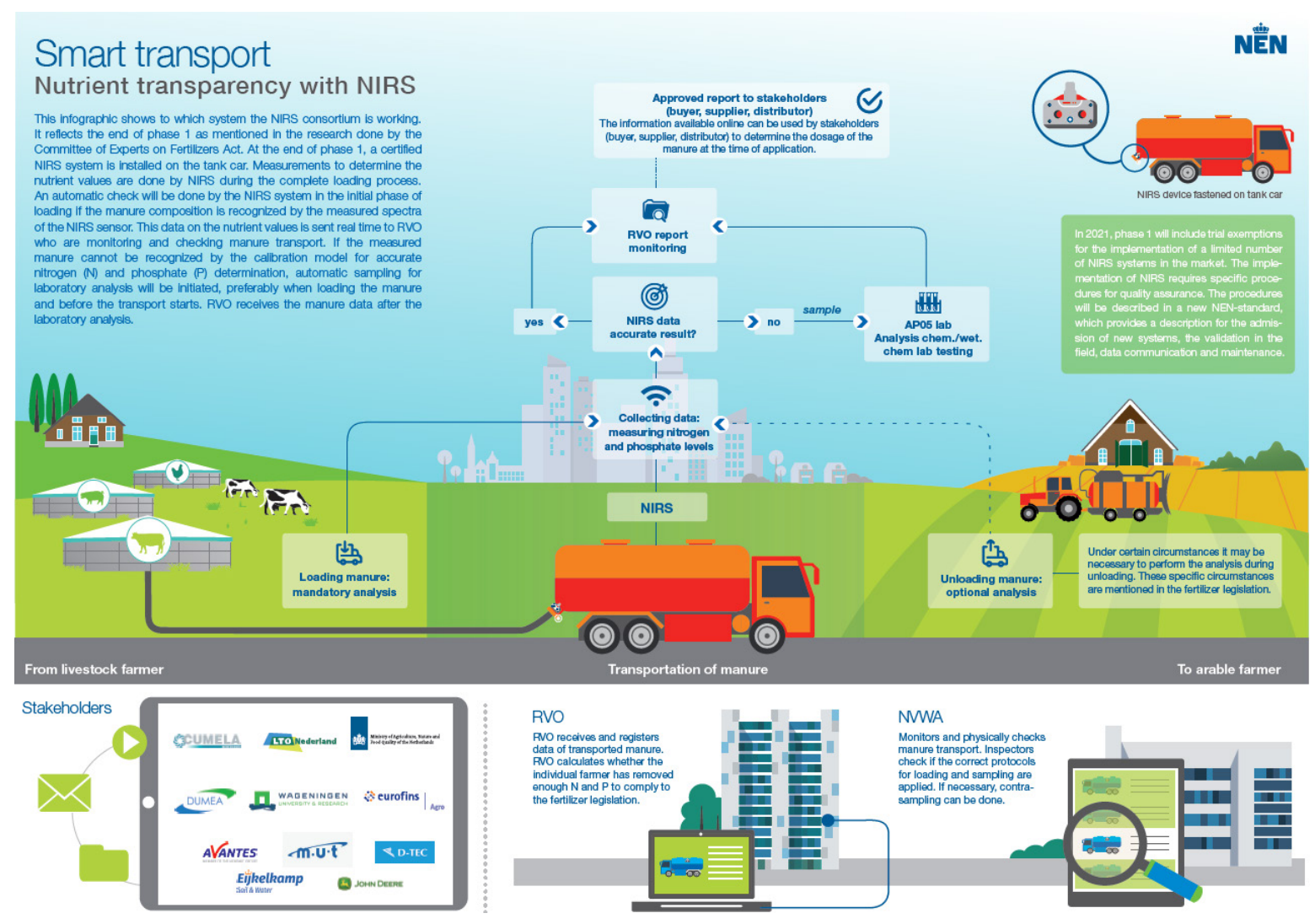

Figure 1 Infographic on the application of NIRS on board of slurry transport vehicles, for an enlarged version see Annex 1.

This report describes the joint research that was performed to gather more information from scientific based research on the performance of NIRS systems. The focus is on the application of NIRS systems on transporting vehicles for animal slurries to estimate the nutrient content. The same technique can be used to enable nutrient based dynamic field application, but this is not within the scope of this project.

\subsection{Developments in on-site fertiliser analysis}

As described in chapter 1.1, more and more sophisticated miniaturized measurement techniques become available to perform on-site analysis, including techniques for fertiliser analysis $(3,5)$. The major advantage of these miniaturized systems is that the analysis can be performed on the spot and results are immediately available. This makes these techniques interesting for users of fertilisers because it allows selective application of the fertiliser. Moreover, these techniques may become a suitable alternative to the current system of sampling and analysis, which is a quite labour-intensive process to determine the nutrient content in fertilisers.

For the on-site determination of the nutrient content of animal slurry various techniques can be used for example: slurry hydrometer, ammonium nitrogen $\left(\mathrm{NH}_{4}-\mathrm{N}\right)$ meter, electrical conductivity, NIRS and Nuclear magnetic resonance (NMR) spectroscopy $(3,5)$.

To our knowledge, NIRS and NMR are currently the only miniaturized techniques for which the future prospects are favourable enough to assume that they could be able to meet the accuracy requirements, as they are currently set for the legal determination of $\mathrm{N}$ and $\mathrm{P}_{2} \mathrm{O}_{5}$ by sampling and analysis $(4,5,6)$. Of these two techniques, NIRS has the advantage that it takes little time to perform a single measurement, allowing for an almost continuous measurement. Therefore, it has the potential to be used for precision 
farming as it can be used to monitor the flow of nutrients upon slurry application. Consequently, this technique has received much attention to be used as measurement device on board of slurry tank trailers and application vehicles and may be suitable for the application on static pipelines. In addition to the estimation of the $\mathrm{N}$ and $\mathrm{P}_{2} \mathrm{O}_{5}$ content, NIRS has shown to be suitable for the estimation of potassium $\left(\mathrm{K}_{2} \mathrm{O}\right)$, dry matter $(\mathrm{DM})$, magnesium $(\mathrm{MgO})$, organic matter $(\mathrm{OM})$ content $(6,7,8,9,10)$ in liquid and solid fertilizing products and may be suitable to determine whether solid fraction after slurry separation has been heat treated (10).

NIRS technology has been demonstrated to have the potential to be used on mobile agricultural equipment with a significant field population being used on harvesting machines and liquid manure application equipment. NIRS technology has also demonstrated the ability to deliver accurate results to measure nutrient ingredients in manure for application equipment in other EU markets like Germany. The Deutsche Landwirtschafts-Gesellschaft (DLG) has developed a test method to evaluate NIR systems for manure ingredient sensing and has officially tested and certified NIR sensors for different types of manure (pig, cattle, biogas digestate) in comparison with multiple certified laboratories.

One major advantage of NMR is that the measurement results are directly related to the total $\mathrm{N}$ and total phosphorus content of the sample, whereas NIRS is an indirect measurement technique. This implies a correlation must be developed between the NIRS spectra and the actual $\mathrm{N}$ and but $\mathrm{P}_{2} \mathrm{O}_{5}$ content of the sample $(4,5)$. Therefore, NMR has the potential to be a very reliable technique. Furthermore, it does not require periodic recalibration like the NIRS systems, where the correlation may change over time because of changes in the feed constituents. Maintaining the NIRS calibration model is a labour-intensive activity that requires laboratory analysis. On the other hand, this process does allow NIRS to continuously improve to provide a more accurate determination.

A disadvantage of NMR is the analysis time and sample size. The analysis requires a small amount of sample and takes a few minutes to provide a sufficiently accurate measurement result. Therefore, NMR is still seen as a technique that needs further development before being applied on board of a manure transport vehicle.

\subsection{General steps and timeline of NIRS implementation}

The introduction of a new tool for accounting for the nutrient content of transported slurry has consequences on a wide range of activities related to the current system. To avoid any unwanted effects on the quality of figures for individual farmers or the system in general a step by step introduction is required. In close cooperation with all parties involved, the Ministry of Agriculture designed the following steps.

NIMACO: Research to determine the performance NIRS systems and obtain the required information to set general guidelines for quality control of the NIRS systems.

Additional R\&D: Additional research to fill the knowledge gaps remaining after NIMACO.

Pilot: Max. 50 vehicles shall be equipped with NIRS next to the conventional system for sampling and analysis. The vehicles may report the NIRS result for the legal determination of the nutrient content if the NIRS measurements meets the quality criteria.

Phase 1: Unlimited number of vehicles may be equipped with NIRS, provided that they meet the performance requirements as stated in Table $1 \mathrm{a}$. This period is used to test and further improve the NIRS systems so that they meet the requirements as stated in Table $1 \mathrm{~b}$ by the end of phase 1.

Phase 2: Unlimited number of vehicles may be equipped with NIRS, provided that they meet the performance requirements as stated in Table $1 \mathrm{~b}$.

Quality assurance: As soon as NIRS systems start reporting actual figures on slurry composition towards the Dutch authorities, the complete system for quality assurance must be in operation. This requires some preparation beforehand. 


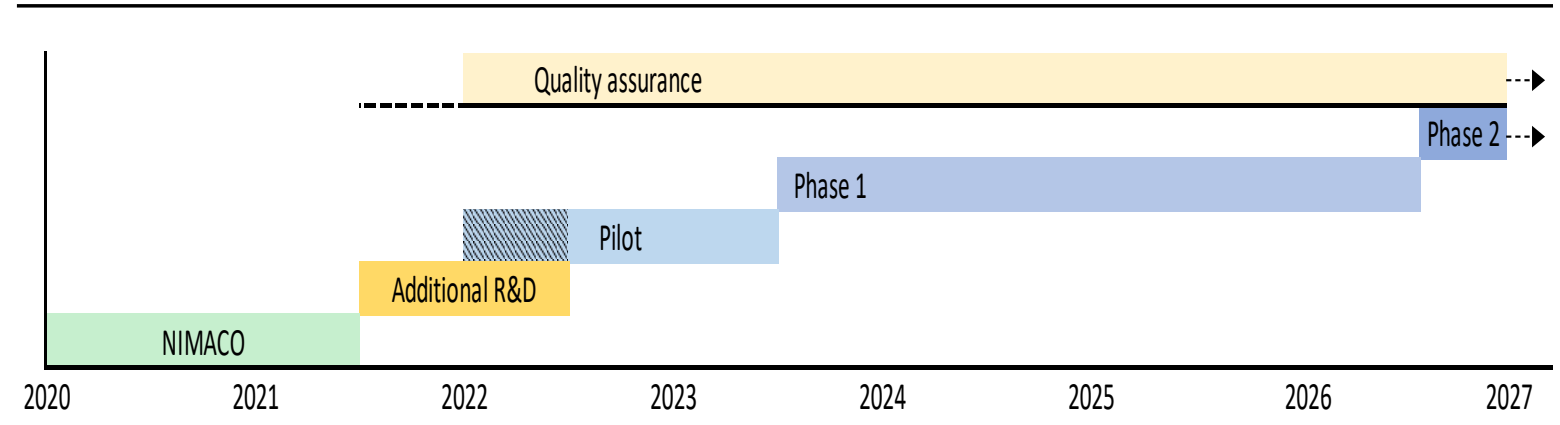

Figure 2 General timeline for the above-mentioned steps for implementation. As moving from one step to the other depends on the progress made so far, no exact deadlines can be set at this stage.

The Scientific Committee on Nutrient Management Policy (CDM) suggested to accept a slightly more tolerant approach towards the accuracy of the NIRS system at the start to allow the technique to improve over time (4). It is seen as a too big step to meet the accuracy of the current system right from the start. The CDM report presented two tables with requirements to be met at the start (Table 1a) and to be met at the beginning of phase 2 (Table $1 \mathrm{~b}$ ).

Table 1a First phase requirements for the maximal systematic and random error for the determination of the $\mathrm{N}$ and $\mathrm{P}_{2} \mathrm{O}_{5}$ content of animal slurry by NIRS applied on board of transport vehicles (for $95 \%$ of the determinations) (4).

\begin{tabular}{llll} 
Element & Concentration & Systematic error & Random error \\
$\mathrm{N}$ & $\leq 2,5 \mathrm{~g} / \mathrm{kg}$ & $<0,125 \mathrm{~g} / \mathrm{kg}$ & $< \pm 0,5 \mathrm{~g} / \mathrm{kg}$ \\
\hline & $>2,5 \mathrm{~g} / \mathrm{kg}$ & $<5 \%$ & $< \pm 20 \%$ \\
\hline $\mathrm{P}_{2} \mathrm{O}_{5}$ & $\leq 0,5 \mathrm{~g} / \mathrm{kg}$ & $<0,025 \mathrm{~g} / \mathrm{kg}$ & $< \pm 0,15 \mathrm{~g} / \mathrm{kg}$ \\
\hline & $>0,5 \mathrm{~g} / \mathrm{kg}$ & $<5 \%$ & $< \pm 30 \%$ \\
\hline
\end{tabular}

Table $1 \boldsymbol{b}$ Second phase requirements for the maximal systematic and random error for the determination of the $\mathrm{N}$ and $\mathrm{P}_{2} \mathrm{O}_{5}$ content of animal slurry by NIRS applied on board of transport vehicles (for $95 \%$ of the determinations) (4).

\begin{tabular}{llll} 
Element & Concentration & Systematic error & Random error \\
$\mathrm{N}$ & $\leq 2,5 \mathrm{~g} / \mathrm{kg}$ & $<0,125 \mathrm{~g} / \mathrm{kg}$ & $< \pm 0,25 \mathrm{~g} / \mathrm{kg}$ \\
\hline & $>2,5 \mathrm{~g} / \mathrm{kg}$ & $<5 \%$ & $< \pm 10 \%$ \\
\hline $\mathrm{P}_{2} \mathrm{O}_{5}$ & $\leq 0,5 \mathrm{~g} / \mathrm{kg}$ & $<0,025 \mathrm{~g} / \mathrm{kg}$ & $< \pm 0,1 \mathrm{~g} / \mathrm{kg}$ \\
\hline & $>0,5 \mathrm{~g} / \mathrm{kg}$ & $<5 \%$ & $< \pm 20 \%$ \\
\hline
\end{tabular}

\subsection{Research within NIMACO}

This research project has been divided into three parts:

1. development of the Proof of Principle protocol (POP) to test NIRS systems under laboratory conditions,

2. development of the Proof of Application protocol (POA) to test the systems under field conditions,

3. the comparison of the current system of sampling and analysis with NIRS analysis under field conditions.

Each of these parts contributes to gather information about the stability and performance of the NIRS systems under laboratory and field operations and acquire the required information to set general guidelines for quality control of the NIRS systems. 


\section{$2 \quad$ NIMACO partners}

This research has been coordinated by Wageningen Food Safety Research and has been carried out in close collaboration with NIRS manufacturers / suppliers (D-TEC, Avantes, John Deere), AP05 accredited laboratories (Eurofins Agro, Normec Dumea), system integrators (D-TEC, Eijkelkamp) and a group of quantitative scientists (Biometris - part of Wageningen Plant Research), as shown below.

Overview NIMACO partners:

Private partners:

AVANTES Avantes B...

MEMBER OF THE NYNOMIC GROUP

\# Normec

Dumea

\section{\&-TEC}

eurofins

Agro

\section{Eij̄kelkamp}

Soil \& Water

\section{JOHN DEERE}

Research partner:

WAGENINGEN L UNIVERSITY \& RESEARCH
Wageningen Food Safety Research

\&

Biometris (part of Wageningen Plant Research) 


\section{Methods}

\subsection{Proof of Principle}

\subsubsection{The POP protocol}

The POP protocol has been developed for the performance assessment of NIRS systems that are used for the determination of the total $\mathrm{N}$ and $\mathrm{P}_{2} \mathrm{O}_{5}$ content in slurry under laboratory conditions. The POP protocol will serve to evaluate whether the NIRS systems meet the performance requirements of Table $1 \mathrm{a}$ in a controlled environment. The POP protocol can serve as a first test before NIRS is applied on board of transport vehicles or to check whether a system still meets the requirements after modifications or calibration updates have been made to the hardware and / or software.

The general principle of POP is that the $\mathrm{N}$ and $\mathrm{P}_{2} \mathrm{O}_{5}$ of a number of test samples is measured with the NIRS system in a controlled laboratory environment and that these results are compared to those determined by laboratory analysis, according to the norms stated in AP05 regulations (2).

Several different experiments and modifications in set up and procedure have led to the final protocol, included as Annex 2. This protocol is handed over to NEN (Royal Netherlands Standardization Institute Foundation) in order to be transformed into an official standard according to the procedure of NEN. This process is under guidance of NEN and NEN will report about the progress independent from this report.

\subsubsection{The POP laboratory setup}

To perform the NIRS measurements, a laboratory measurement setup was developed to display a continuous flow of homogenized sample in front of the NIRS sensor.

The developed measurement setup consists of the following components:

- Peristaltic pump

- Stirrer

- Flow cell with a horizontal cross section $60 \times 40 \mathrm{~mm}$

- Pump hose

- Sample container

The exact details of the equipment are mentioned in the Proof of Principle protocol, see Annex 2. These components are combined as shown in Figure 3.

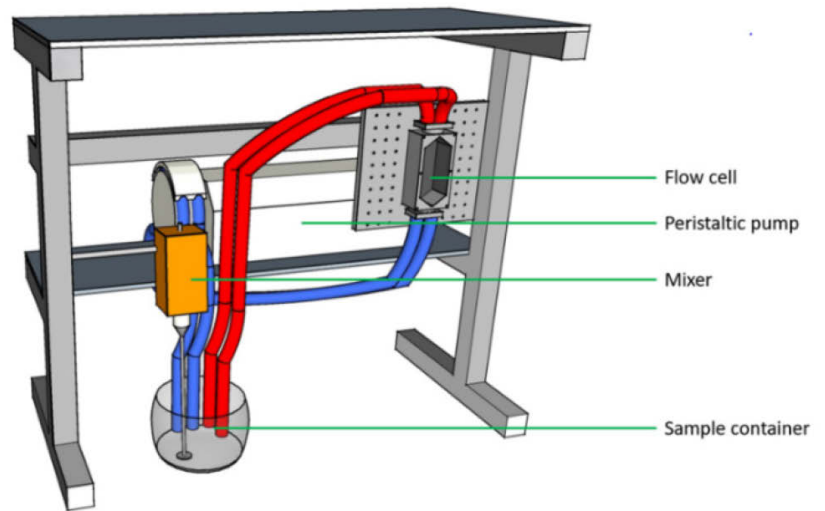

Figure 3 Schematic representation of the Proof of Principle laboratory setup 
The stirrer is used to mix the slurry and keep the slurry homogenized. The peristaltic pump is used to pump the slurry through the flow cell, to which the NIRS system was mounted. In the first design, a flow cell was used with a cross section of $25 \mathrm{~mm}$ wide and $5 \mathrm{~mm}$ deep. At a later stage, this flow cell was replaced by a flow cell with a cross section of $60 \mathrm{~mm}$ wide and $40 \mathrm{~mm}$ deep, as shown in detail in Annex 2. This adjustment was made to prevent potential interferences from the back wall of the flow cell. In the final design two hoses are used to supply a steady continuous flow of slurry to the flow cell (blue) and two hoses are used to transport the slurry back into the sample container (red). The two hoses are needed to provide the desired flow rate of slurry in the flow cell with the given limitations of hose diameters in combination with the pump heads used.

A more detailed drawing of the flow cell has been included as appendix of the POP protocol, see Annex 2. In this final design the NIRS system is mounted to the front cover of the flow cell. A metal front cover has been custom made for each NIRS system to ensure a liquid tight mount of each system to the flow cell.

\subsubsection{Composition of the slurry samples}

A set of approximately 20 samples was prepared for testing the NIRS systems with the Proof of Principle. These samples consist of slurry or mixtures of slurries and were prepared to have a diverse $\mathrm{N}$ and $\mathrm{P}_{2} \mathrm{O}_{5}$ content that are realistic for Dutch slurry, based on the history of $\mathrm{N}$ and $\mathrm{P}_{2} \mathrm{O}_{5}$ concentrations that were determined for relevant slurry transports in the period January 2020 till December 2020. The N, $\mathrm{P}_{2} \mathrm{O}_{5}$, dry matter and organic matter content were determined according to AP05 regulations (2) and NEN7432:1998 (11). The samples were stored at $4 \pm 3{ }^{\circ} \mathrm{C}$ and a periodically check was carried out to monitor the $\mathrm{N}$ and $\mathrm{P}_{2} \mathrm{O}_{5}$ content. Additionally, the test set was periodically refreshed by replacement of a number of test samples with freshly collected slurry samples from different farms. A file was kept up-to date with the composition and $\mathrm{N}$ and $\mathrm{P}_{2} \mathrm{O}_{5}$ content of each sample.

\subsubsection{POP measurements}

First a number of preparatory measurements were performed to ensure the laboratory setup does properly presents the slurry in front of the NIRS sensor. For a good representation of the slurry it is important that the slurry is homogeneous and that no air bubbles are present in the slurry.

Air may either be introduced through the inlet as a result of stirring the slurry mixture, or through connections that are not properly sealed. The latter was prevented in the final design of the flow cell by pumping the liquid from the pump to the flow cell instead of suction of the liquid through the cell. This creates an overpressure inside the flow cell that will result in leakage instead of suction of air into the slurry. The presence of air in the system was checked by using a transparent front cover and pumping water through the flow cell and performing a visual check to see if air bubbles are present in the flow cell or exiting the outlet of the pump hoses.

Furthermore, it was checked whether stirring and pumping the manure is sufficient to homogenize the slurry. This is especially important for the measurement of $\mathrm{P}_{2} \mathrm{O}_{5}$ which is largely present in the solid particles, which can settle on the bottom of the sample container if the slurry is not mixed sufficiently. This was checked for three samples by collecting two samples one from the top and one from the bottom of the slurry inside the sample container, after 15 and $45 \mathrm{~min}$ of stirring and pumping according the POP protocol. The dry matter content of these samples was analysed according to NEN7432:1998 (11) to determine if any sedimentation occurs.

Subsequently, a number of test samples were measured with each NIRS system. The NIRS spectra of these samples were shared with corresponding supplier to check whether the NIRS spectra were in the line of expectation and to check for any interferences present that may be caused by the laboratory setup. Based on the feedback of the suppliers the flow cell was replaced by a flow cell with a greater distance between the sensor and back wall of the flow cell to avoid potential interferences from the back wall of the flow cell as a result from scattering and reflection of light. In addition, an experiment was performed to evaluate the stability of the measured $\mathrm{N}$ and $\mathrm{P}_{2} \mathrm{O}_{5}$ in respect to the set flowrate. For this test, three samples were measured at a set flowrate of 4, 8, 12, 16, 20 and $24 \mathrm{~L} / \mathrm{min}$. 
Each NIRS supplier was given the opportunity to have their system assessed multiple times. For these measurements, all test samples with a $\mathrm{N}$ and $\mathrm{P}_{2} \mathrm{O}_{5}$ content within the concentration range specified by the NIRS supplier were included in the evaluation. Additionally, the analysis of at least three samples was repeated on another day to check if the results were repeatable.

\subsubsection{Evaluation POP measurements}

A standard procedure has been set to assess the NIRS system against the performance requirements set for NIRS. The methodology for this assessment has been developed in collaboration with Biometris. The procedure is encapsulated in a script, to enable the quick and uniform assessment of the POP results. This script evaluates the random and systematic error of the NIRS system in relation to the $\mathrm{N}$ and $\mathrm{P}_{2} \mathrm{O}_{5}$ content in the test samples. The NIRS system passes the POP with a positive result if both the random and systematic error meet the set performance requirements. In Annex 3 , a more detailed description of the data analysis is given. The supplier of the NIRS system is informed by WFSR about the findings in a short report.

\subsection{Proof of Application}

The Proof of Application protocol has been developed for the performance assessment of NIRS systems that are used on board of an individual slurry transport vehicles for the determination of the total $\mathrm{P}_{2} \mathrm{O}_{5}$ and $\mathrm{N}$ content, see Annex 4. This method is applied as a check to test whether the NIRS system on board of an individual transport vehicle meets the performance requirements for the legal determination of $\mathrm{N}$ and $\mathrm{P}_{2} \mathrm{O}_{5}$ in slurry according to the Dutch Fertilizer Law. Within this report we refer to the term transport vehicles, but application vehicles which are registered for transport are meant as well.

The POA performance assessment can serve three purposes:

1. initial approval/certification of an individual transport vehicle in combination with a given NIRS system,

2. periodically quality assurance checks,

3. unannounced quality inspections.

\subsubsection{The POA approach}

The general idea behind the developed POA is that the overall estimated $\mathrm{N}$ and $\mathrm{P}_{2} \mathrm{O}_{5}$ concentration by NIRS system upon loading a tank trailer shall be compared to the measurement results from laboratory analysis of an ideal sample of the truck load.

For this assessment it is important that very accurate and precise results are obtained from laboratory analysis, which is performed according the NEN norms stated in AP05 regulations. In addition, the sample for laboratory analysis must be highly representative for the contents of the trailer. In order to obtain this representative sample, the trailer content is thoroughly mixed before the sample is acquired. This is achieved by transferring slurry content of the transport vehicle completely into an external tank (or test trailer). When the transfer is completed the slurry is mixed by recirculating the slurry with the pump. Upon circulation, the slurry is pumped through a conventional sampling device that shall be used to collect the representative sample when trailer content is sufficiently homogenized. This sample is analysed in the laboratory according the norms in AP05 regulations (2) and the results shall be used to evaluate performance of the NIRS equipment. 


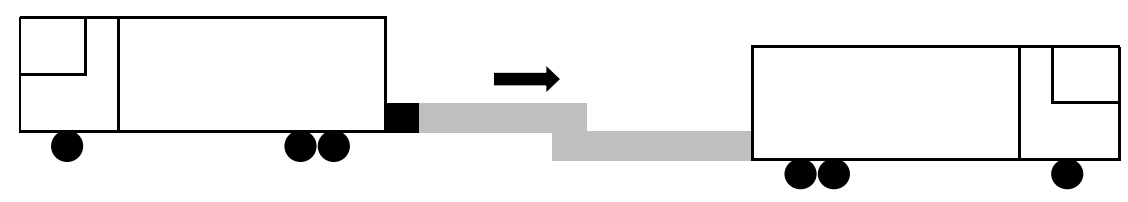

take over of the load
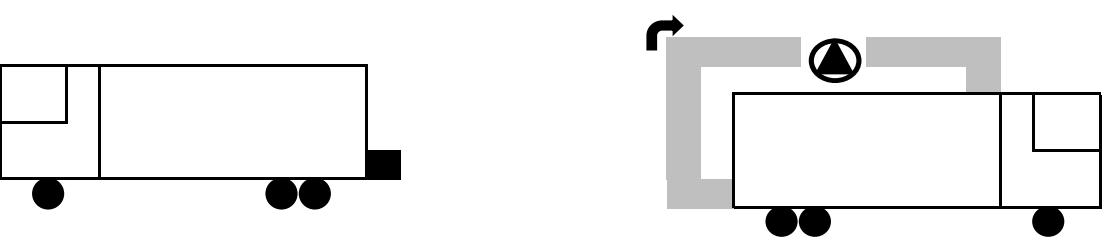

mixing and sampling

re charging the load

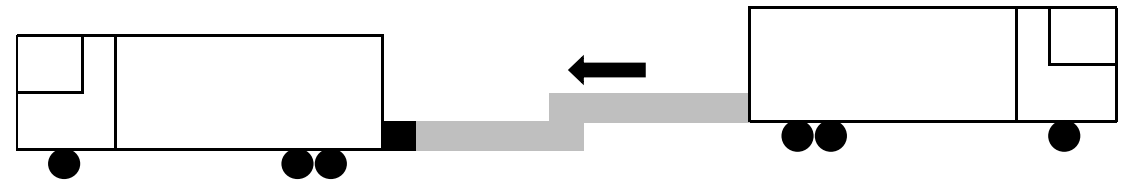

Figure 4 Schematic representation of the process for collecting the representative POA sample.

\subsubsection{POA experiments}

For testing whether the drafted POA protocol is suitable for assessment of the performance of the NIRS equipment on a trailer, a commercial trailer is adapted to be used as a test trailer. The adaption made was a software change that uncouples the control of the sampling device from the degree of loading of the tank. This allows the operator of the test trailer, to manually start the sampling equipment as soon as the mixing is completed, next to the regular option to automatically perform sampling upon loading of the test vehicle.

In order to check whether the protocol for the POA is technically executable and suitable for the collection of a representative sample of the trailer content a number of tests were performed. These tests were performed to check whether the internal circulation of slurry over the pump of the test trailer is sufficient to homogenize a fully loaded trailer. For these tests the test trailer with a capacity of $36 \mathrm{~m}^{3}$ was completely filled with slurry from an inhomogeneous slurry storage. Then, the slurry was internally recirculated with the pump for one hour. During this hour, approximately every 6 minutes a sample was collected using the conventional sampling device. These samples were transported to the laboratory and then stored at $4 \pm 3^{\circ} \mathrm{C}$, until laboratory analysis. The $\mathrm{N}, \mathrm{P}_{2} \mathrm{O}_{5}$, dry matter and organic matter content of these samples were determined according to the NEN norms stated in AP05 regulations (2) and NEN 7432:1998 (11). The results are presented graphically versus the mixing time.

This experiment has been performed seven times with independent slurry loads. Due to the time required to collect the samples and seal the sample bag, a maximum of three portions of slurry were collected in one sample bag for cattle and pig slurry, respectively manure code (MC) 14 and 50 . When using sows and piglets slurry, MC 46, only one portion was sampled in one separate bag. This was done to get a better understanding of the differences between individual collected portions.

Furthermore, some experiments were performed to evaluate the assessment procedure developed for the POA. However, since no NIRS equipped vehicles were available, this evaluation has been done with the laboratory analysis results of the current system of sampling and the analysis and those of the ideal sample, which was obtained according the final POA protocol. However, instead of filling the trailer with contents of the transport vehicle, the trailer was filled from an inhomogeneous slurry storage. Upon loading the trailer, a sample was collected according to the conventional sample procedure for sampling and analysis. This results in the collection of 6 subsamples, into one sample bag when the trailer filled between 20 to $80 \%$. Then, the contents of the test trailer were recirculated 
over the pump (mixed) for 15 minutes, after which a sample was taken by collection of three portions of slurry into the sample bag. In total, this test has been performed 14 times for various types of slurry, roughly in line with the proportion in which they are transported in the Netherlands, shown in Table 2.

Table 2 The selection of inhomogeneous slurry storage.

\begin{tabular}{clll} 
Manure code (MC) & Slurry originating from & Number of tests \\
\hline 14 & Cattle & 4 \\
\hline 50 & Pigs & 4 \\
\hline 46 & Sows and piglets & 2 \\
\hline 18 & Calf (white meat) & 2 \\
\hline 19 & Calf (rosé meat) & 2 \\
\hline
\end{tabular}

For the $7^{\text {th }}(M C 50), 10^{\text {th }}$ (MC 14) and $11^{\text {th }}$ (MC 14) test, the trailer could only be filled to degree of $33 \%, 90 \%$ and $80 \%$, respectively. In case of the $7^{\text {th }}$ test, sampling procedure upon loading was not completely finished and only 3 out of 6 subsamples were collected in the sample bag.

\subsubsection{Evaluation POA measurements}

A standard procedure has been set to process the POA results to assess the performance of the NIRS system for the measurement of $\mathrm{N}$ and $\mathrm{P}_{2} \mathrm{O}_{5}$, against the performance requirements stated in Table $1 \mathrm{a}$ and $1 \mathrm{~b}$.

The evaluation of the POA-results will be done at two levels. First of all on individual tank trailer level, and second, by comparison to the results of all individual tank trailers that are equipped with the same type of NIRS system. The intention of these evaluations is to identify any erroneous system as quick as possible within the limits of inspection frequency.

For the evaluation of individual vehicles, a Shewhart chart like approach is used to monitor the POA test results of each individual tank trailer over time. In this chart the POA results will be displayed based on their z-score, as shown in Figure 5.

The $z$-score is calculated by the formula:

Z-score $=\frac{x_{N I R S}-\mu}{\sigma_{\operatorname{Max}}}$

with:

$x_{\text {NIRS }}=$ NIRS result in $\mathrm{g} / \mathrm{kg}$

$\mu \quad=$ Wet chemical analysis result in $\mathrm{g} / \mathrm{kg}$

$\sigma_{\text {Max }}=$ Maximal allowed random standard deviation

$\sigma_{\text {Max }}$ is derived from the limits that apply for $95 \%$ measurements of the transports performed with the transport vehicle. Initially, $\sigma_{\text {Max }}$ and thus the $2 \sigma$ and $3 \sigma$-limits shall be set based on the performance criteria set for the random error in Table $1 \mathrm{a}$. The allowed systematic error is not taken into account in this interval, as this could lead to approval of systems with too large random error. 


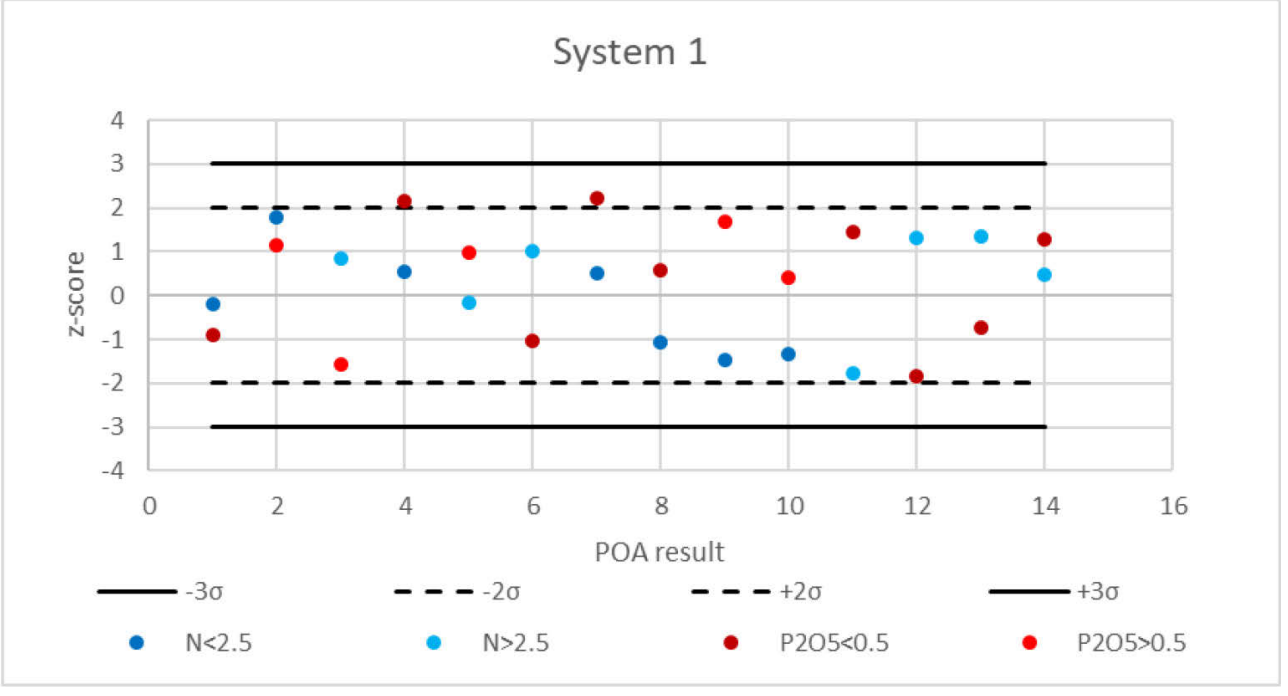

Figure 5 Example of how a control chart for an individual NIRS system could look like, showing the z-score of consecutive POA results for $\mathrm{N}$ and $\mathrm{P}_{2} \mathrm{O}_{5}$.

A joint evaluation of all systems of the same type of NIRS system will be carried out, focusing particularly on the systematic error of the system. For this purpose, the results of all the trailers with the same type of NIRS on board are combined with the wet chemical analysis results. Visual inspection of the NIRS values plotted against the wet chemical analysis results is carried out to explore the deviation for the range of concentrations that was considered. In addition, it is tested if the average difference between the NIRS and wet chemical value is within the limits given by the measuring technique. The latter is similar to the quality assurance program currently applied to the performance of the commercial AP05 laboratories (2).

\subsection{Comparison of NIRS and conventional Sampling and Analysis}

\subsubsection{The principle of the comparison study}

The comparison study between the NIRS system and the conventional sampling and analyses is required to obtain further information:

- to evaluate the performance of the NIRS systems under field conditions,

- to determine the stability of the systems,

- to quantify the benefits of performing continuous measurements upon loading,

- to prepare for real-time communication of data to RVO,

- to set guidelines for periodical quality assurance checks of the NIRS systems.

In this comparison study NIRS shall be used in the background on commercial slurry transport vehicles. The current system for sampling and analyses shall be used to account for the nutrient content of the transport. In this period two transport vehicles for each participating NIRS supplier shall be equipped with NIRS in addition to the conventional system for sampling and analysis. Then each transport vehicle should preferably perform at least 200 transports that are monitored with the NIRS system. The NIRS data obtained shall only be used for research purposes.

The comparison study should provide answers to the following questions:

1. how does the average result of NIRS measurements taken at the moment of subsampling compare to the AP05 laboratory results of sampling and analysis?

2. how much do the NIRS readings fluctuate over the loading period of the trailer?

3. how stable is the NIRS equipment on a trailer under everyday circumstances over a longer period in time? 
The second question, was not addressed in the pilot performed in 2017 (8), but now has been added as it provides the information to quantify the advantage of the continuous NIRS measurement compared to the current system where 5 - 9 subsamples are collected for analysis upon loading.

Furthermore, previous research has shown that special care must be taken to ensure that the samples of the transports are not included into a "mengmonster", thus combined with samples from other transports for analysis. Both Eurofins Agro and Normec Dumea indicated that their laboratories are willing to cooperate to ensure these samples are not included in a "mengmonster".

\subsubsection{Preparation for the comparison study}

This comparison study was intended to start after the NIRS systems would have passed the POP successfully. However, the progress of the NIMACO project has been hampered by the COVID-19 pandemic almost from the start of the project, due to the (temporary) unavailability or traveling limitations of specialists and serious limitations in the physical exchange of equipment and samples to be examined.

The NIRS systems that were provided by the NIRS suppliers did not pass the POP successfully and the suppliers only had little time to improve their system. Consequently, no vehicles were equipped with NIRS to prepare for this comparison study.

To prepare for the comparison study, a document was drafted in consultation with the involved parties that describes the data that should be collected for each transport. In Figure 6, an example is shown of an excel data-format with all information to be collected for each transport. The data must be collected and transferred to WUR within 24 hours of the executed transport to ensure reliability.

\begin{tabular}{|c|c|c|c|c|}
\hline Date (DD:MM:YY) & $01-07-21$ & & & \\
\hline ID Trailer (numeric) & 437624 & & & \\
\hline VDM number (numeric) & 9107591365 & & & \\
\hline Time (HH:MM:SS) & $08: 45: 00$ & & & \\
\hline Dominant mestcode & 14 & & & \\
\hline Temparature ambient (numeric in ${ }^{\circ} \mathrm{C}$ ) & 18,0 & & & \\
\hline \multicolumn{5}{|c|}{\begin{tabular}{|l|l|} 
Temparature slurry (numeric in ${ }^{\circ} \mathrm{C}$ ) & \\
\end{tabular}} \\
\hline \multicolumn{5}{|c|}{ Data with italic header is optional, leave blank if no data is available. } \\
\hline \multicolumn{5}{|c|}{ *Indicates the NIRS measurements that are recorded when a subsample is collected by the conventional sampling system. } \\
\hline Timestamp (HH:MM:SS) & ID NIRS spectrum (numeric) & Subsample moment* $(0=$ no $; 1=$ yes $)$ & $\mathrm{N}(\mathrm{g} / \mathrm{kg})$ & $\mathrm{P}_{2} \mathrm{O}_{5}(\mathrm{~g} / \mathrm{kg}$ \\
\hline 08:45:00 & 35897595 & 0 & 3,54 & 1,07 \\
\hline 08:45:45 & 35897595 & 0 & 3,57 & 1,28 \\
\hline 08:46:30 & 35897595 & 0 & 3,79 & 1,15 \\
\hline 08:47:15 & 35897595 & 0 & 3,84 & 1,02 \\
\hline 08:48:00 & 35897595 & 0 & 3,99 & 1,28 \\
\hline $08: 48: 45$ & 35897595 & 0 & 3,54 & 1,29 \\
\hline 08:49:30 & 35897595 & 0 & 3,54 & 1,29 \\
\hline $08: 50: 15$ & 35897595 & 0 & 3,82 & 1,10 \\
\hline 08:51:00 & 35897595 & 0 & 3,65 & 1,17 \\
\hline $08: 51: 45$ & 35897595 & 0 & 3,79 & 1,29 \\
\hline 08:52:30 & 35897595 & 0 & 3,52 & 1,07 \\
\hline 08:53:15 & 35897595 & 0 & 3,80 & 1,15 \\
\hline 08:54:00 & 35897595 & 0 & 3,95 & 1,04 \\
\hline $08: 54: 45$ & 35897595 & 0 & 3,84 & 1,30 \\
\hline 08:55:30 & 35897595 & 0 & 3,98 & 1,02 \\
\hline 08:56:15 & 35897595 & 0 & 3,99 & 1,10 \\
\hline 08:57:00 & 35897595 & 0 & 3,72 & 1,24 \\
\hline 08:57:45 & 35897595 & 1 & 3,62 & 1,12 \\
\hline $08: 58: 30$ & 35897595 & 1 & 4,00 & 1,26 \\
\hline 08:59:15 & 35897595 & 1 & 3,61 & 1,13 \\
\hline 09:00:00 & 35897595 & 0 & 3,80 & 1,27 \\
\hline
\end{tabular}

Figure 6 An example of a part of the Excel data-collection format that must be completed and collected the for each individual transport monitored for the comparison study. Containing some general information about the transport and NIRS measurement data over the entire loading time. In this example only a few rows with measurement data are shown, in practice this may be several hundred measurements for each transport. 


\section{$4 \quad$ Results \& discussion}

\subsection{Proof of Principle}

After a couple of adjustments to the initial design, the POP laboratory setup as shown in Figure 7 was deemed suitable for the performance assessment of NIRS systems under laboratory conditions. This was based on the stability of the NIRS signal and the feedback of the NIRS suppliers who received the measurement data.

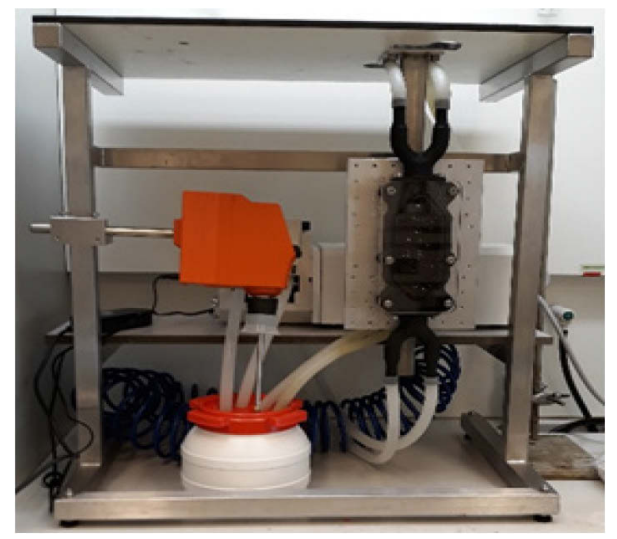

Figure $7 \quad$ POP laboratory setup. When performing NIRS measurements the transparent front cover is replaced by a metal cover to which the NIRS system can be mounted.

The primary adjustment to the initial setup was increasing the depth of the flow cell to avoid potential interferences that might have been present from the reflection of light from the back wall of the flow cell. Consequently, to maintain the desired stable continuous flowrate in the flow cell the pump speed and the number of hoses were increased.

In Table 3 the results of the homogeneity versus time for three different samples is shown.

Table 3 Results homogeneity test of POP samples during the NIRS measurement.

\begin{tabular}{|c|c|c|c|c|c|c|c|}
\hline & Time stirring & Sample & & & & & \\
\hline Sample & & 1 & & 2 & & 3 & \\
\hline Sample point & & Upper* & Lower* & Upper* & Lower* & Upper* & Lower* \\
\hline DM (g/kg) & $45 \min$ & 67,68 & 68,34 & 24,35 & 25,13 & 75,38 & 77,95 \\
\hline
\end{tabular}

* The upper samples were slurry collected near the upper-surface of the slurry; lower samples were slurry samples collected near the bottom of the sample container.

These three samples show that, if present, only limited segregation of solid particles occurs. The degree of segregation does not seem to increase when the mixing time (measurement) is extended from 15 to 45 minutes. 
In Figure 8 the influence of the set flowrate is shown in relation to the measured $\mathrm{N}$ and $\mathrm{P}_{2} \mathrm{O}_{5}$ concentration by one of the NIRS systems.

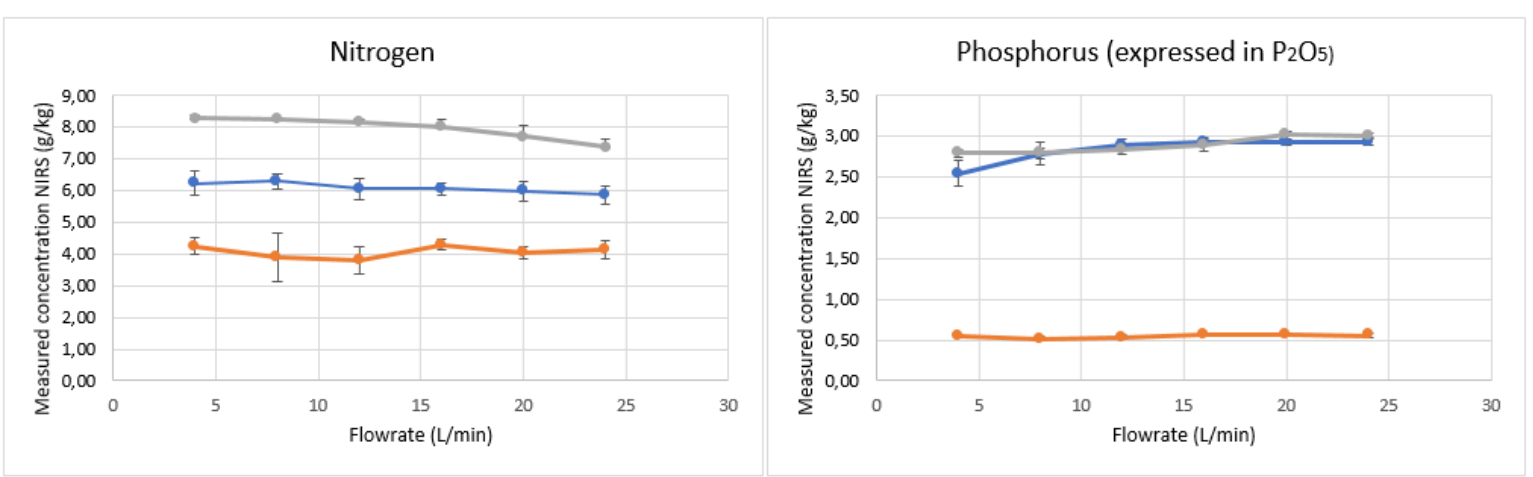

Figure 8 Estimated $\mathrm{N}$ and $\mathrm{P}_{2} \mathrm{O}_{5}$ concentration by NIRS in relation to the set flow rate for three different samples (assigned with different colours), the error bars show the standard deviation of the measurements.

A flowrate of $16 \mathrm{~L} / \mathrm{min}$ has been selected for the final POP protocol, as it provides a stable continuous flow and stable NIRS readout for the $\mathrm{N}$ and $\mathrm{P}_{2} \mathrm{O}_{5}$ content even when the flowrate may deviate $\pm 20 \%$.

Furthermore, the procedure for preparing the slurry samples was adjusted. Initially samples were composed of slurry, mixtures of slurries, water and solid fraction after slurry separation to obtain test samples with a wide range of $\mathrm{N}$ and $\mathrm{P}_{2} \mathrm{O}_{5}$ contents. However, the NIRS suppliers pointed out that samples containing solid fraction or an excessive additional amount of water resulted in NIRS spectra that were not in-line with spectra that were usually obtained for real transports. Therefore, the use of solid fraction after slurry separation and addition of water in the samples was omitted.

To date, the NIRS suppliers have not succeeded to supply a NIRS system that meets the first phase performance requirements stated in the CDM report for $\mathrm{N}$ nor $\mathrm{P}_{2} \mathrm{O}_{5}$, (see Table 1a). Based on the obtained POP results the NIRS systems do not meet the requirements for the systematic nor random error. Due to the pandemic situation, there has been too limited time to perform sufficient proof of principle tests and further develop calibrations by the NIRS suppliers. Nonetheless the results of the NIRS systems have improved over time, by adjustments that were made to both the POP laboratory set-up and the systems themselves, mainly in the software part.

NIRS suppliers are dedicated to make further improvements in hard-/software to obtain a positive result from the POP measurements in the near future. It is the intention to keep the experimental setup of the POP evaluation up and running for future use.

\subsection{Proof of Application}

A POA protocol has been developed for the assessment of NIRS systems that are on board of slurry transport vehicles for the measurement of $\mathrm{N}$ and $\mathrm{P}_{2} \mathrm{O}_{5}$ in slurry under field conditions.

The tank trailer that was used to perform the Proof of Application experiments is shown in Figure 9.

The results of seven tests that were performed to investigate whether internal recirculation of slurry over the pump of the test trailer is sufficient to homogenize the trailer content are shown in Figure 10 graph $A$ \& $B$. Based on these figures the fluctuations in $\mathrm{N}$ and $\mathrm{P}_{2} \mathrm{O}_{5}$ seem to be very limited from the start of the mixing procedure. 


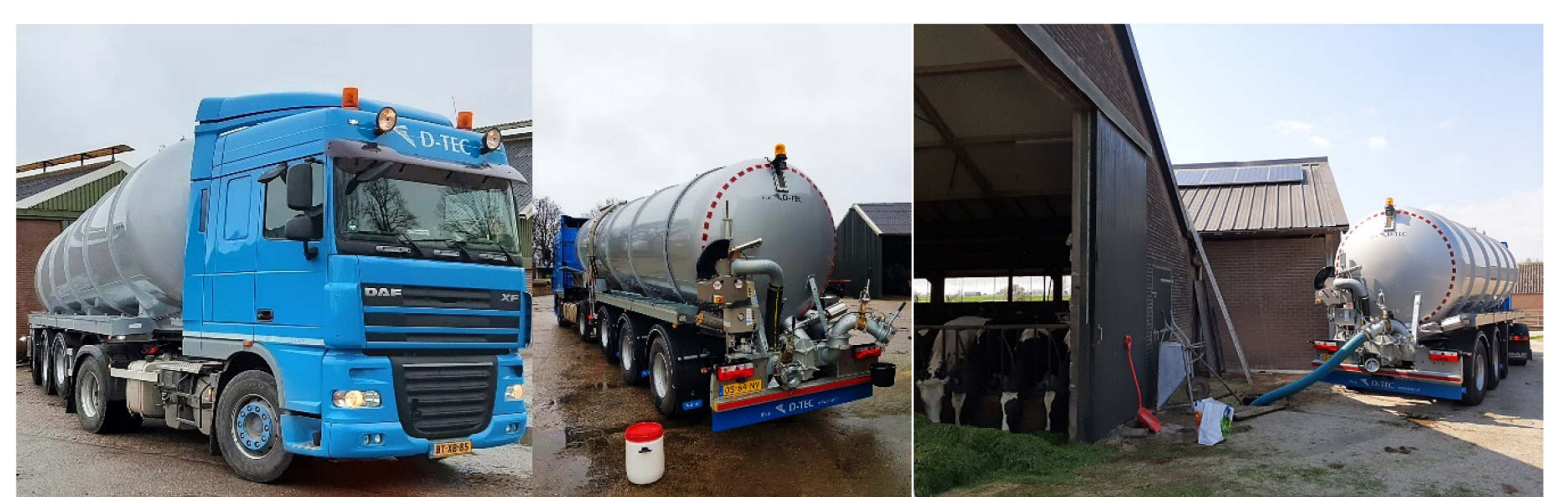

Figure 9 Tank trailer that has been used to perform the POA experiments.

Figure 10 graph $C \& D$ shows the deviation of each of the samples to the average content of the last three samples of that load, taken after at least 36 min mixing. The deviation in the measured concentration appears to decrease with longer mixing of the trailer content. The deviation of the $\mathrm{N}$ content in the samples is less than $\pm 3 \%$ after 15 minutes of mixing; the deviation of the $\mathrm{P}_{2} \mathrm{O}_{5}$ content in the samples to the stabilized value is below $\pm 5 \%$ after 15 minutes of mixing for most of the transports.

For the two tests with MC46, only one subsample of slurry was collected into the sample bag. These two tests seem to have a slightly larger fluctuation in $\mathrm{N}$ and $\mathrm{P}_{2} \mathrm{O}_{5}$ content. It may be caused by a larger sampling error due to the collection of only one subsample instead of three subsamples of slurry. This shows that the trailer content is only slightly heterogeneous after 15 minutes of mixing of a freshly loaded volume of slurry from an unmixed storage.

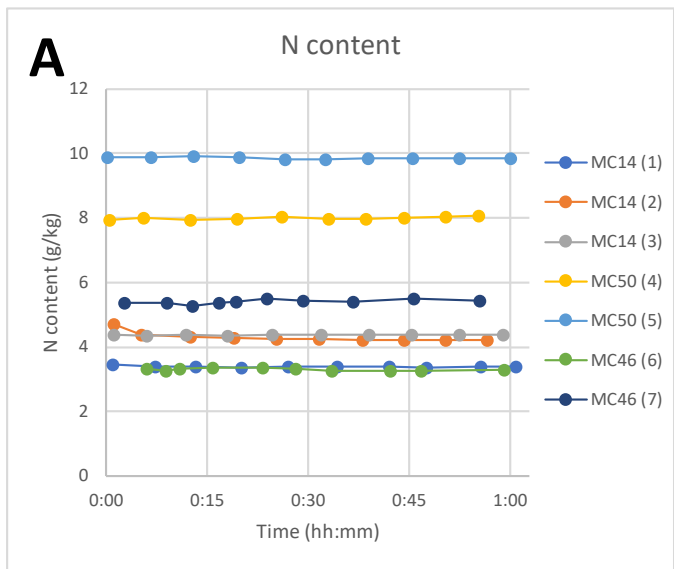

C Deviation of $\mathrm{N}$ content to average of

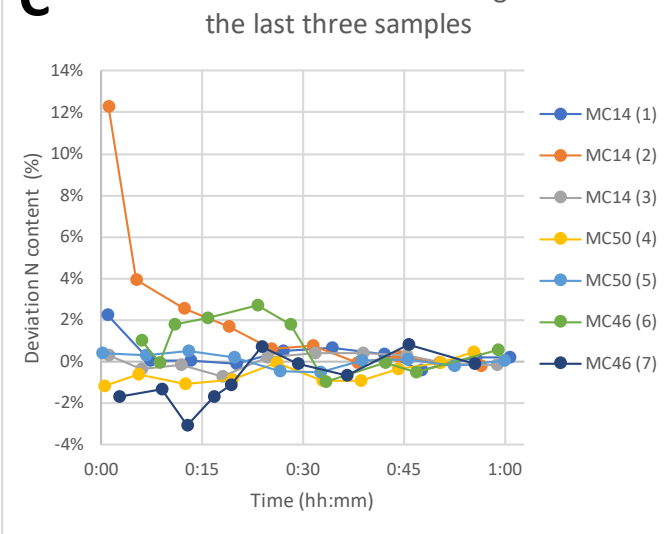

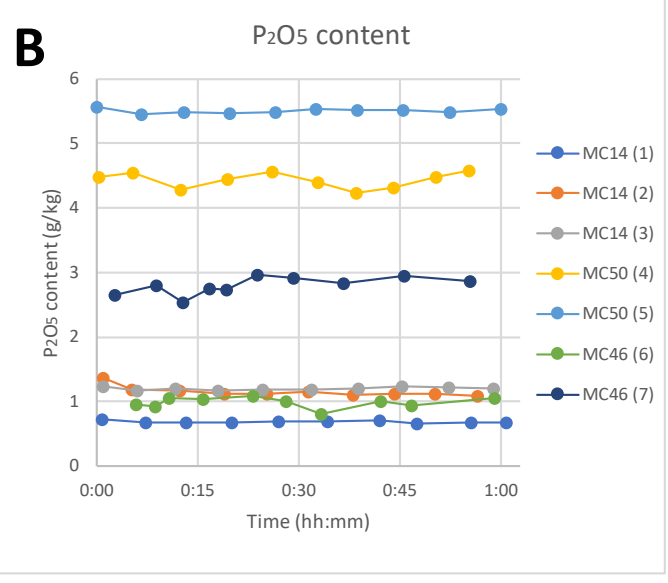

D Deviation of $\mathrm{P}_{2} \mathrm{O} 5$ content to average of the last three samples

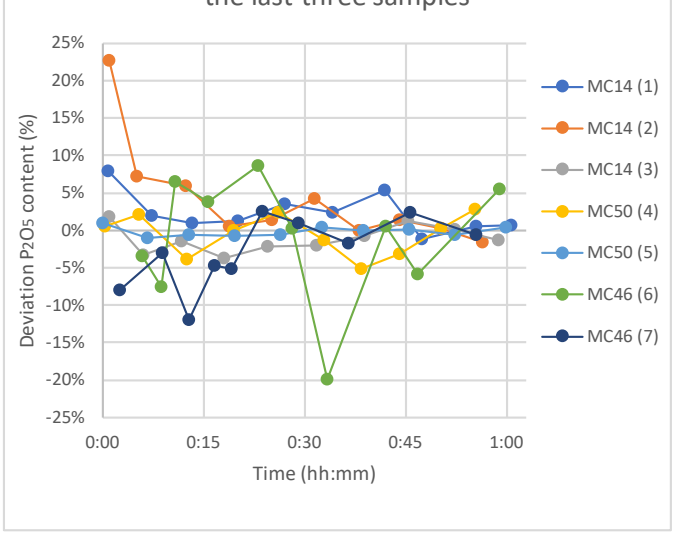

Figure 10 Results of the POA mixing tests. $A$ \& $B$ : The $N$ and $P_{2} \mathrm{O}_{5}$ content of collected samples ( $A$ \& $B) ; C \& D$ : The deviation in $N \& P_{2} O_{5}$ content for each sample in respect to the average of the last three samples of the corresponding slurry load. 
Furthermore, 5 - 9 subsamples (current procedure for AP05 samples) shall be collected as the POA sample is collected according to the official POA protocol. This shall further reduce the sampling error, resulting in a more representative sample. This will most likely prevent fluctuations as they appear for MC 46 (7).

Figure 11 shows laboratory analysis results for the comparison of the conventional system of sampling and the sample collected by the POA protocol. The black line in Figure 11 visualises the ideal line for the POA results. Furthermore, the concentration range of $\mathrm{N} \& \mathrm{P}_{2} \mathrm{O}_{5}$ in the samples for each of the individual manure codes is shown in Table 4.
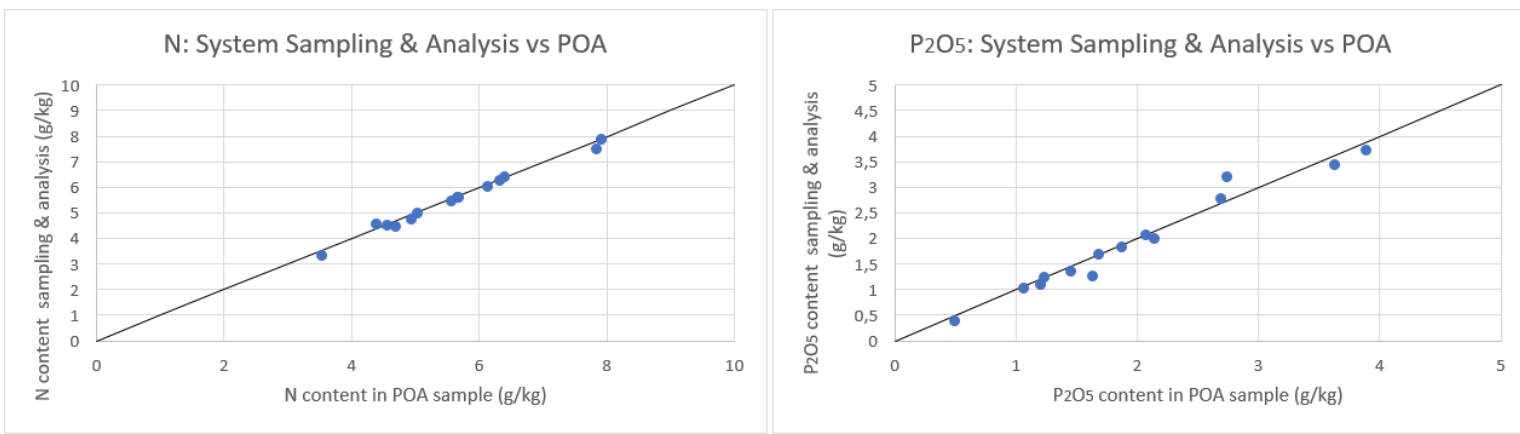

Figure 11 Overview of the wet chemical results of the samples taken by conventional system of sampling and analysis and the POA samples.

In Figure 12 these results are visualised in a control chart based on the z-score for each POA as described in chapter 3.2.3. Each POA measurement of this test is interpreted as a consecutive POA measurement in order to evaluate the conventional system of sampling and analysis according the developed POA statistical assessment procedure. The z-scores are calculated using $\sigma_{\text {Max }}=0,5 *$ maximum allowed random error in stated in Table $1 \mathrm{a}$, as the limits apply for $95 \%$ of the measurements that are performed with the transport vehicle.

The tests that were performed with a not completely filled tank $\left(7^{\text {th }}, 10^{\text {th }}\right.$ and $\left.11^{\text {th }}\right)$ have also been included, as these tests do not show any major deviation compared to the other results.

Table $4 \quad \mathrm{~N} \& \mathrm{P}_{2} \mathrm{O}_{5}$ concentration range of the POA samples.

\begin{tabular}{lllll} 
Tests no. & Manure code $(\mathrm{MC})$ & Slurry type & $\mathrm{N}$ range $(\mathrm{g} / \mathrm{kg})$ & $\mathrm{P}_{2} \mathrm{O}_{5} \mathrm{range}(\mathrm{g} / \mathrm{kg})$ \\
\hline $1 \& 2$ & 18 & Calf (white meat) & $4,56-5,66$ & $1,46-1,69$ \\
\hline $3 \& 4$ & 19 & Calf (rosé meat) & $6,13-6,33$ & $1,87-2,07$ \\
\hline $5-8$ & 50 & Pig & $5,64-7,92$ & $1,14-3,89$ \\
\hline $9-12$ & 14 & Bovine & $4,69-5,67$ & $0,50-1,24$ \\
\hline $13 \& 14$ & 46 & Sows and piglets & $3,54-4,38$ & $1,62-2,74$ \\
\hline
\end{tabular}




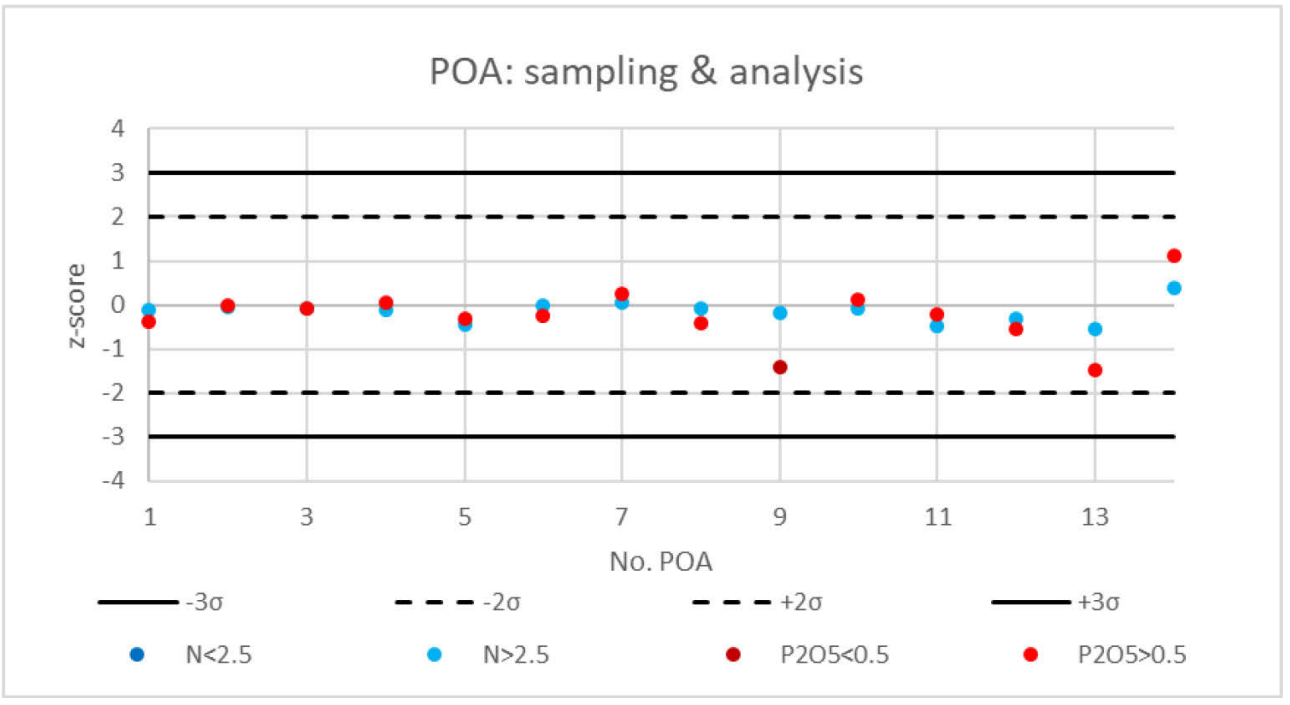

Figure 12 Evaluation of the POA results for the system of and analysis.

The results shown in Figure 11 and Figure 12 are in line with the expectations. The system of sampling and analysis does not exceed the $\pm 2 \sigma$ interval, and passed every POA test successfully if evaluated against the phase 1 performance requirements for NIRS.

Though, it is worth mentioning that test 13 and 14 have a relatively large $z$-score compared to the other tests. These were the only tests performed with sow and piglets slurry, MC 46. Therefore, consideration should be given to pay extra attention to investigate whether this is related to the type of slurry. The observed fluctuations are still well within the $\pm 2 \sigma$ interval. 


\section{Conclusion \& recommendations}

Based on this research the following conclusions can be formulated:

- A POP laboratory setup and protocol has been developed for the assessment of NIRS systems for the determination of $\mathrm{N}$ and $\mathrm{P}_{2} \mathrm{O}_{5}$ in slurry under laboratory conditions. This protocol is currently at NEN to be established as a formal NEN document by a standard procedure in consultation of public parties as well.

- The progress of the NIMACO project has been hampered by the pandemic almost from the start of the project, due to the unavailability or traveling limitations of specialists and serious limitations in the physical exchange of equipment and samples to be examined. Due to this, there has been too limited time to perform sufficient proof of principle tests and further develop calibrations. Therefore, the NIRS suppliers have not yet succeeded to supply a NIRS system that meets the first phase performance requirements stated in the CDM report for $\mathrm{N}$ nor $\mathrm{P}_{2} \mathrm{O}_{5}$, see Table $1 \mathrm{a}$. However, the results of the NIRS systems have improved over time, by adjustments that were made to both the POP laboratory set-up and the NIRS systems.

- A protocol for the POA has been prepared for the assessment of NIRS equipment on board of an individual tank trailer for the determination of $\mathrm{N}$ and $\mathrm{P}_{2} \mathrm{O}_{5}$. Several initial tests have been performed to evaluate whether this protocol seemed suitable for the evaluation of the NIRS systems. This protocol is currently at NEN to be established as a formal NEN document by a standard procedure in consultation of public parties as well.

- Comparison of NIRS and sampling \& analysis has not been performed within the timeframe of this research project. Preparations are made and the research will be carried out within a separate project indicated as additional research in Figure 2. In addition, the investigation to compare the benefits of continuous sampling using the NIRS method versus limited samples per load and lab analysis still has to be conducted.

Based on the current research, the following recommendations are made for future investigations:

- As surrounding countries encounter similar difficulties with (regional) nutrient surpluses originating from animal slurries, it might be helpful to come to international quality assurance procedures for NIRS systems. The German Verband Deutscher Maschinen- und Anlagenbau (VDMA) has established a working group with subject matter experts and developed a draft international standard for NIRS technology to measure nutrient content in liquid manure. This is planned to be officially published through the CEN organization. It would be of high interest to harmonise the planned NEN activities and standards with the international standards.

- Future developments might result in alternatives for NIRS, therefore it is recommended to keep an eye on alternative techniques, like NMR. For the time being, NIRS is the only practically applicable technique to evaluate the nutrient content in animal slurries. It has the advantage that it allows continuous measuring and therefore takes into account any fluctuation in nutrient content of the slurry over the total loading process. 


\section{References}

1. Ministerie van Landbouw, Natuur en Voedselkwaliteit (2020) Nederlandse mestbeleid 2019. Retrieved from: https://www.rijksoverheid.nl/documenten/rapporten/2020/06/01/rapportagenederlands-mestbeleid-2019

2. Law uitvoeringsregeling Meststoffenwet, Annex $\mathrm{H}$ Accreditatieprogramma dierlijke mest; AP05

3. Snauwaert, E. et al. (2016) On Farm Tools for accurate fertilization. EIP-AGRI Focus Group Nutrient recycling. Retrieved from:

https://ec.europa.eu/eip/agriculture/sites/default/files/2_mp_on_farm_tools_final.pdf

4. Commissie Deskundigen Meststoffenwet, 2018. Advies bepaling van nutriënten via NIRS. Retrieved from: https://www.wur.nl/upload_mm/c/1/4/ff867572-9fdc-4184-af24-

35ee3cbe9cbd_1837341_CDMadvies\%20bepaling\%20van\%20nutrienten\%20in\%20dierlijke\%20mest\%20via\%20NIRS.pdf

5. Sørensen, M.K. (2015) NPK NMR Sensor: Online Monitoring of Nitrogen, Phosphorus, and Potassium in Animal Slurry. Analytical Chemistry, 87(13), 6446-6450

6. Chen, L. (2013) Review of the Application of Near-Infrared Spectroscopy Technology to Determine the Chemical Composition of Animal Manure. Journal of Environmental Quality, 42, 1015-1028

7. Van de Zedde, R., Kekem van, K., Boer, E. (2014) Bemonsteren en analyseren van dierlijke mest op een vrachtauto - B012.07-006-004. Wageningen UR Food \& Biohazard Research, Retrieved from: https://edepot.wur.nl/304191

8. Hoeksma, P., Aarnink, A. (2017) Bepaling van het stikstof- en fosfaatgehalte van een vracht drijfmest door middel van Nabij Infra Rood Spectroscopie (NIRS) - resultaten van een pilot, Wageningen UR Livestock Research. Retrieved from: https://www.wur.nl/upload_mm/a/4/c/5c9bacd0-7f55-4bbd-bd963500d33d11bf_1719219_Oene\%200enema\%20bijlage\%201.pdf

9. Rietra, R.P.J.J., Oenema, O. (2017) Bepaling van vaste mest met NIRS. Wageningen UR Environmental Research. Retrieved from: https://research.wur.nl/en/publications/bepalingsamenstelling-van-vaste-mest-met-nirs

10. Derikx, P.J.L. et al. (2020) Nabij-infrarood spectroscopie (NIRS) voor de hygiënisatie bepaling van de dikke fractie mest na mestscheiding. Wageningen UR Food Safety Research. Retrieved from: https://research.wur.nl/en/publications/nabij-infrarood-spectroscopie-nirs-voor-de-hygienisatiebepaling-

11. Norm commission "Meststoffen" (2018) NEN 7432: Manure and derivatives - Determination of the contents of dry matter and organic matter - Gravimetric method [NEN Connect]. Retrieved from: https://www.nen.nl/nen-iso-7432-2018-en-250973 


\section{Annex 1 Infographic on the application of NIRS}

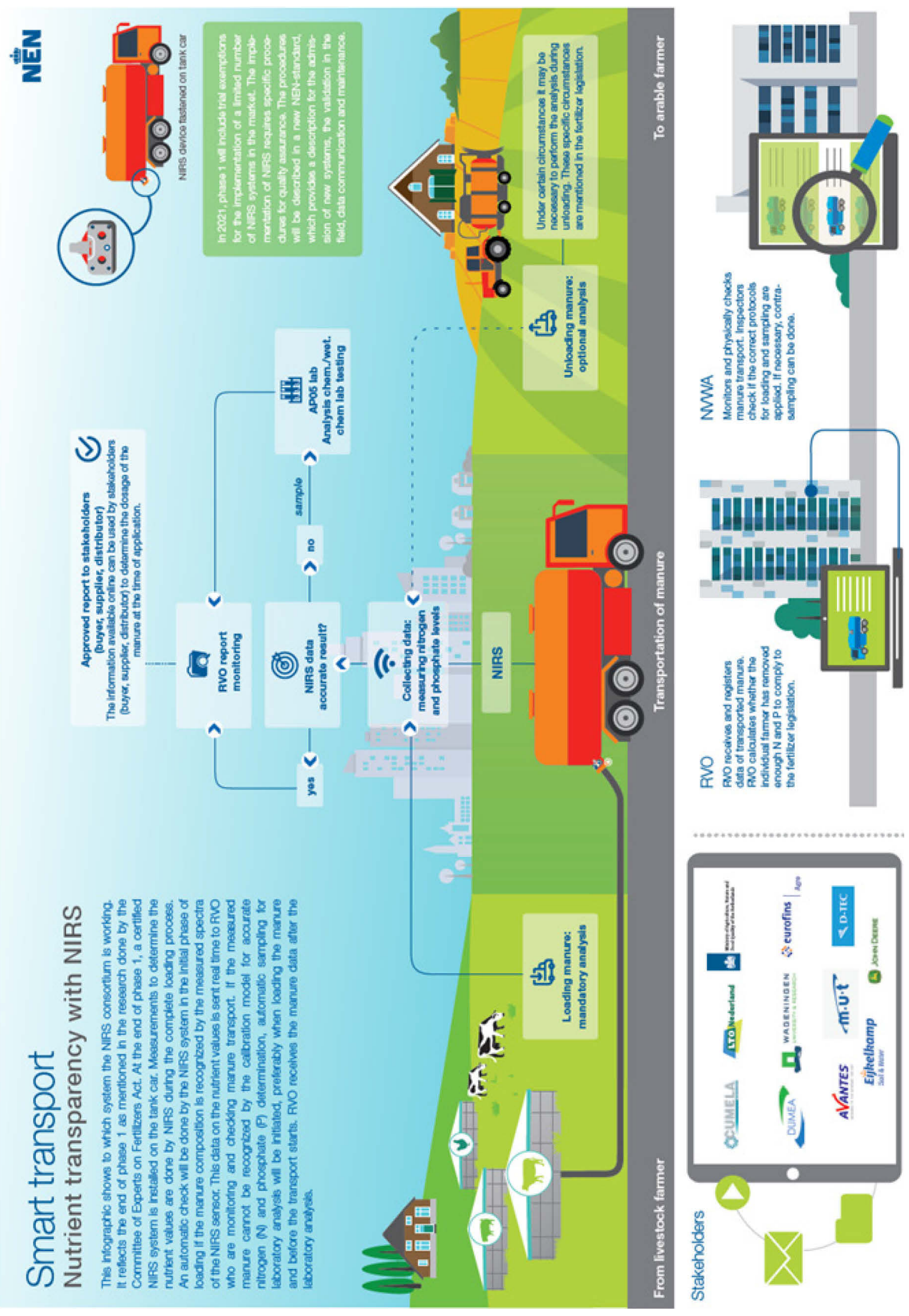




\section{Annex 2 POP protocol}

Version: June 2021

\section{Scope}

This document defines the method for the performance assessment of systems that are to be used on board of tank trailers for the determination of the total nitrogen $(\mathrm{N})$ and total phosphorus $\left(\mathrm{P}_{2} \mathrm{O}_{5}\right)$ content in slurry. This method is applied as a check to test whether the systems meet the performance criteria for the legal determination of the $\mathrm{N}$ and $\mathrm{P}_{2} \mathrm{O}_{5}$ content in slurry in the Netherlands.

The maximum $\mathrm{N} \& \mathrm{P}_{2} \mathrm{O}_{5}$ concentration ranges for which the system shall be evaluated are set by values derived from the current situation in the Netherlands. The supplier of the NIRS system can narrow the concentration ranges for which a given NIRS shall be evaluated, this shall be specified in the final report.

At the moment of writing, this protocol can only be applied for the performance assessment of NIRS systems. In the future, it may be applied to other type of systems if research has shown that the method is suitable for that type of systems.

\section{Terms and definitions}

For the purposes of this document, the following term and definition apply.

Slurry

Mixture of animal excreta with water, feed residues and/or bedding material with a constituent which allows it to be transported by pumping.

\section{Principle}

The performance of the NIRS system shall be evaluated by comparing the measured $\mathrm{N}$ and $\mathrm{P}_{2} \mathrm{O}_{5}$ concentrations by the NIRS system to those determined by laboratory analysis according to NEN standards mentioned in accreditation protocol AP05 [1].

\section{Materials and equipment}

\section{$4.1 \quad$ Slurry samples}

A set of approximately 20 samples with a volume of 2 to $2.5 \mathrm{~L}$ shall be used for testing the NIRS system. These samples consist of slurry or mixtures of slurries and have a diverse $\mathrm{N}$ and $\mathrm{P}_{2} \mathrm{O}_{5}$ concentrations that are realistic for Dutch slurry. The $\mathrm{N}, \mathrm{P}_{2} \mathrm{O}_{5}$, dry matter and organic matter content in the test samples shall be determined according to NEN standards mentioned in AP05 and NEN 7432:1998 [2]. The samples must be stored at $(4 \pm 3)^{\circ} \mathrm{C}$ and a periodical check shall be carried out using a selection of the test set to check the stability of the $\mathrm{N}$ and $\mathrm{P}_{2} \mathrm{O}_{5}$ content in the test samples over time. In addition, the set of test samples must periodically be refreshed by replacement of some of the test samples with freshly collected slurry samples. The frequency with which the concentration check and replacement is required is determined based on the perceived stability of the slurry 
samples. Experimental history data and the accumulated results of $\mathrm{N}$ and $\mathrm{P}_{2} \mathrm{O}_{5}$ analysis of each sample in the sample set shall be registered.

\section{$4.2 \quad$ Equipment}

\subsubsection{Peristaltic pump}

A peristaltic pump with a capacity of $16 \mathrm{~L}$ slurry/min shall be used.

\subsubsection{Mechanical stirrer}

A stirrer able to homogenize slurry samples in the container (4.2.5.).

\subsubsection{Flow cell}

A flow cell with a horizontal cross section of $60 \times 40 \mathrm{~mm}$ shall be used. The front cover of the flow cell must be developed specifically to fit the NIRS system according to the specifications provided by the NIRS supplier. Furthermore, flow cell must be designed so that no ambient light enters the flow cell. The flow cell should be made of a material that does not cause excessive reflection of near-infrared radiation.

\subsubsection{Pump hoses}

\subsubsection{Sample container}

A sample container with a minimal volume of $2.5 \mathrm{~L}$.

\subsubsection{The POP measurement setup}

The pump (4.2.1.), mechanical stirrer (4.2.2.), flow cell (4.2.3.), sample container (4.2.5.) should be combined as shown in Figure A2.1. The mixing head of the stirrer must be positioned inside the sample container in such way that it shall ensure that the sample is thoroughly mixed without introducing air bubbles in the sample. The peristaltic pump shall be used to pump the slurry through the hoses to the flow cell, to which the NIRS system shall be mounted. The front cover of the flow cell serves as a mounting plate for the NIRS system. A detailed technical drawing of the flow cell has been included in Appendix B1.

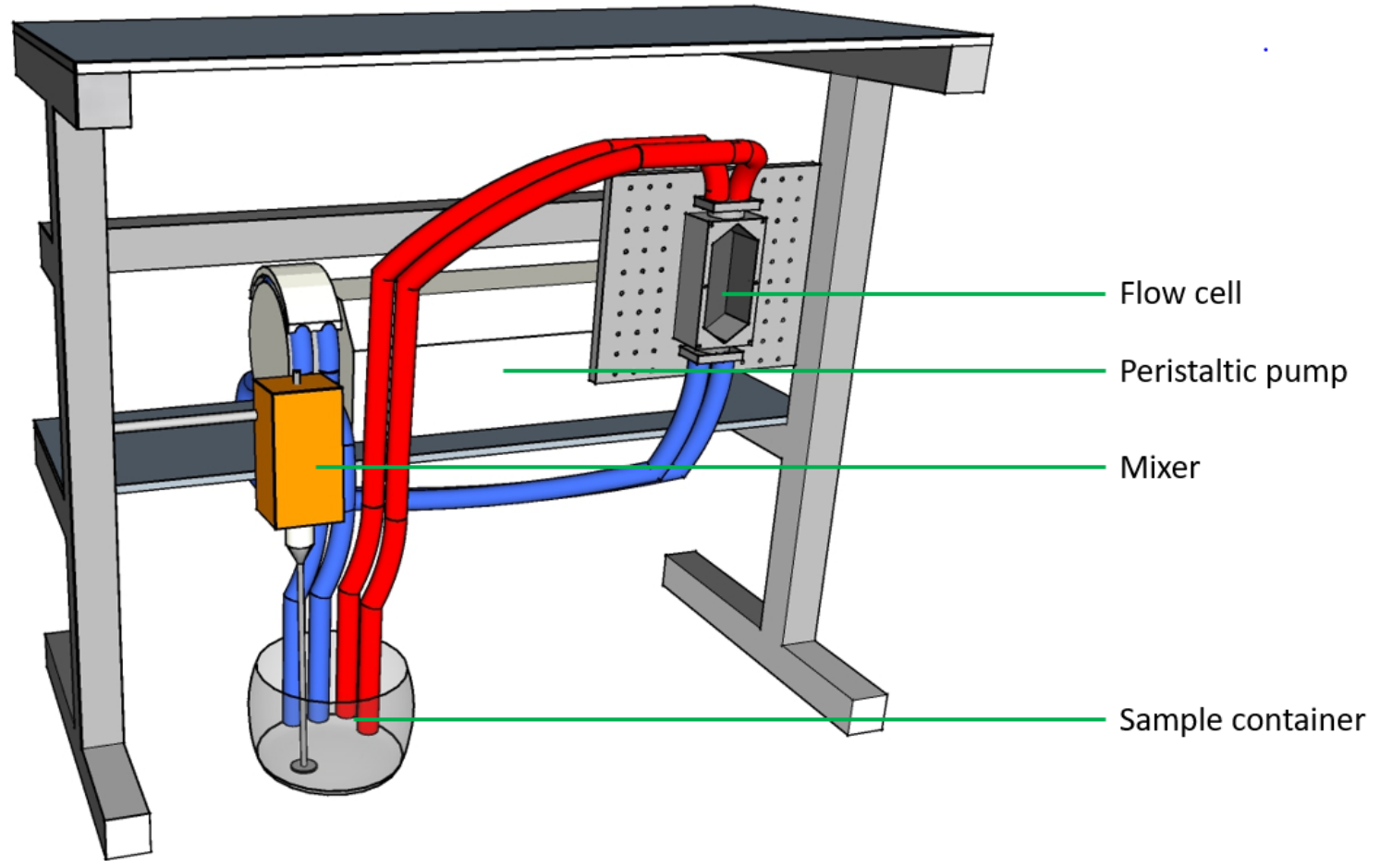

Figure A2.1 Schematic illustration of the Proof of Principle laboratory setup with the hoses for the inlet in blue and outlet in red 


\section{Procedure}

\subsection{NIRS analysis of the slurry samples}

The following actions must be performed by the operator to perform the NIRS measurements:

1. Condition the test samples at room temperature $\left(18-24^{\circ} \mathrm{C}\right)$.

2. Prepare the laboratory setup (4.2.6.) and mount the NIRS system onto the flow cell using the front cover that is specially designed to fit the NIRS system. The first time a NIRS system is evaluated, the supplier of the NIRS system shall be contacted to confirm that NIRS system is installed correctly.

3. Visually check whether the front cover with the attached NIRS system sufficiently seals the flow cell, so that a tight connection is obtained. The first time a NIRS system is evaluated, step $4-6$ should be performed with a sample container filled with water instead of slurry to check for possible leaks.

4. Remove the lid of one of the sample containers and place the head of the mixer, and in- and outlets of the pump hoses inside of the sample container.

5. Ensure that the head of the mixer and inlet are completely submerged in the slurry.

6. Start the mixer and set the mixer to a speed at which the slurry is thoroughly mixed.

7. Start the pump and set the flowrate to $16 \mathrm{~L} / \mathrm{min}$. For every sample the actual flowrate should be checked, a maximum deviation $20 \%$ from the desired flowrate is allowed. If the desired flowrate is not achieved, adjust the torque on the hose or adjust the set flowrate to obtain the desired flowrate.

8. Check by visual inspection if air is introduced into the flow cell. If that is the case, adjust the height of the mixer and/or inlet of the pump to avoid suction of air. Furthermore, the speed of the mixer shall be adjusted if necessary, taking into account that slurry must still be thoroughly mixed.

9. Start the NIRS measurement, when the setup has stabilized, according to the description prescribed by the provider of the NIRS system. The prescribed method should provide a readout of the $\mathrm{N} \& \mathrm{P}_{2} \mathrm{O}_{5}$ concentration within 5 minutes of analyzing the test sample.

10. When the NIRS measurement is finished, switch off the mixer and pump and drain the slurry from the pump hoses and flow cell into the sample container.

11. Replace the sample container with a sample container filled with water and close the sample container with the lid. Pump the water through the system for some time and drain the system into a waste container. Repeat this rinsing procedure until no slurry is visually present.

12. Repeat steps $4-11$ for all slurry samples.

13. Store the samples at $(4 \pm 3)^{\circ} \mathrm{C}$.

14. Repeat the entire procedure, steps 1 to 13 , for at least 3 samples after at least 12 hour storage.

\section{Evaluation of the measurement results}

\subsection{Assessment procedure}

For the assessment of the performance of the NIRS system the measured $\mathrm{N}$ and $\mathrm{P}_{2} \mathrm{O}_{5}$ concentration by NIRS system shall be compared to the measurement results from laboratory analysis according the NEN standards stated in AP05. This comparison shall be performed by evaluation of the agreement of the log-log regression of the NIRS values and results from laboratory analysis. Using regression analysis, the systematic error and random error of the NIR system shall be statistically evaluated for the measurement of $\mathrm{N}$ and $\mathrm{P}_{2} \mathrm{O}_{5}$ in slurry. In general the maximum allowed deviation of the measured value from the true value is relative to the concentration from the critical point upwards. Below the critical point the deviation is constant and independent from the concentration. This is shown by the solid blue line in Figure A2.2. 


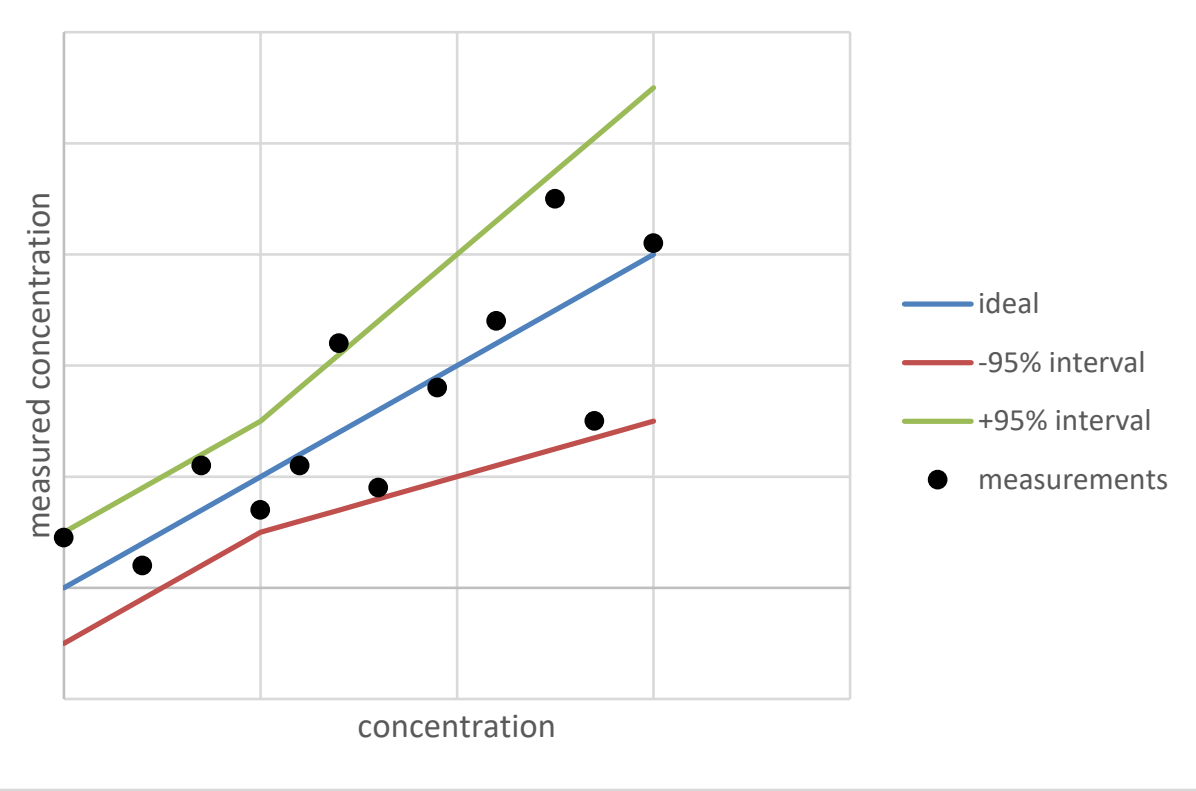

Figure A2.2 Schematic representation of measurement results and the 95\% interval of the allowed deviation around the ideal situation, based on the given performance criteria.

\subsubsection{Systematic error}

The assessment of the systematic error of the NIRS system for both the determination of the $\mathrm{N}$ and $\mathrm{P}_{2} \mathrm{O}_{5}$ concentration must be performed based on the evaluation of the estimated relative systematic differences between the all result of two methods to the maximum allowed systematic error (6.2.).

The NIRS system meets the POP performance criteria for the systematic error when the $95 \%$ confidence interval of the systematic difference does not exceed the specified maximum allowed systematic error (6.2.). A confidence interval outside the maximum allowed range implies that the data is not informative enough to statistically show the absence of meaningful systematic deviations. This may occur even when the true systematic error of the system is small, due to the maximum allowed random deviation (6.2).*

*Therefore, for the current stage of the introduction of NIRS where NIRS results are not yet applied for the legal determination of the nutrient content, it was decided to evaluate the systematic error by visual inspection of the results. The minimum requirement for the system to be approved this way is that the point estimate of the systematic error falls within the limits for the maximum allowed deviation. It may necessary to increase the POP sample size, to be able to statistically determine that the systematic error of NIRS falls within the allowed limits (6.2).

\subsubsection{Random error}

The assessment of the random error for all measurement results is based on a comparison of a 2-sided tolerance interval of the relative error to the maximum allowed error. This tolerance interval shall, with $95 \%$ confidence, contain $95 \%$ the relative random error of at least $95 \%$ of the slurry samples that would be analysed in the future by the system.

The NIRS system meets the POP performance criteria for the random error when the 95/95\% 2-sided tolerance interval for the random error for all the measurement results does not exceed the specified maximum allowed random error (6.2.).

\subsection{Performance requirements}

The minimal performance requirements to obtain a positive POP result for the determination of total $\mathrm{N}$ and $\mathrm{P}_{2} \mathrm{O}_{5}$ concentration for the specified concentration range is dependent on the introduction phase of NIRS. During the first phase of the introduction of NIRS, the NIRS systems should at least meet the performance requirements stated in Table A2.1. 
It is foreseen that over time the requirements will become more stringent after Phase 1 has ended. The exact moment in time has to be decided by the Ministry of Agriculture. The performance requirements for phase 2 are given in Table A2.2.

Table A2.1 Phase 1 performance requirements for the maximum systematic random error for the NIRS measurements of $\mathrm{N}$ and $\mathrm{P}_{2} \mathrm{O}_{5}$ in slurry [3].

\begin{tabular}{llll} 
Element & Concentration level & Systematic error & Random error \\
Nitrogen $(\mathrm{N})$ & $\leq 2,5 \mathrm{~g} / \mathrm{kg}$ & $<0,125 \mathrm{~g} / \mathrm{kg}$ & $<0,5 \mathrm{~g} / \mathrm{kg}$ \\
\hline & $>2,5 \mathrm{~g} / \mathrm{kg}$ & $<5 \%$ & $<20 \%$ \\
\hline Phosphorus $\left(\mathrm{P}_{2} \mathrm{O}_{5}\right)$ & $\leq 0,5 \mathrm{~g} / \mathrm{kg}$ & $<0,025 \mathrm{~g} / \mathrm{kg}$ & $<0,15 \mathrm{~g} / \mathrm{kg}$ \\
\hline & $>0,5 \mathrm{~g} / \mathrm{kg}$ & $<5 \%$ & $<30 \%$ \\
\hline
\end{tabular}

Table A2.2 Phase 2 performance requirements for the maximum systematic random error for the NIRS measurements of $\mathrm{N}$ and $\mathrm{P}_{2} \mathrm{O}_{5}$ in slurry [3].

\begin{tabular}{llll} 
Element & Concentration level & Systematic error & Random error \\
Nitrogen $(\mathrm{N})$ & $\leq 2,5 \mathrm{~g} / \mathrm{kg}$ & $<0,125 \mathrm{~g} / \mathrm{kg}$ & $<0,25 \mathrm{~g} / \mathrm{kg}$ \\
\hline & $>2,5 \mathrm{~g} / \mathrm{kg}$ & $<5 \%$ & $<10 \%$ \\
\hline Phosphorus $\left(\mathrm{P}_{2} \mathrm{O}_{5}\right)$ & $\leq 0,5 \mathrm{~g} / \mathrm{kg}$ & $<0,025 \mathrm{~g} / \mathrm{kg}$ & $<0,1 \mathrm{~g} / \mathrm{kg}$ \\
\hline & $>0,5 \mathrm{~g} / \mathrm{kg}$ & $<5 \%$ & $<20 \%$ \\
\hline
\end{tabular}

\section{Report of the results}

The report shall at least contain the following information:

a. The date of the NIRS measurement

b. The NIRS supplier

c. Equipment specifications

d. The $\mathrm{N}$ and $\mathrm{P}_{2} \mathrm{O}_{5}$ concentration range in $\mathrm{g} / \mathrm{kg}$ for which the system is evaluated

e. A figure showing the $\mathrm{P}_{2} \mathrm{O}_{5}$ concentration in the slurry measured by NIRS system and by laboratory analysis according AP05

f. A figure showing the total $\mathrm{N}$ concentration in the slurry measured by NIRS system and by laboratory analysis according AP05

g. Whether the NIRS successfully passed the current requirements.

\section{References}

1. Law uitvoeringsregeling Meststoffenwet, Annex H Accreditatieprogramma dierlijke mest; AP05

2. NEN 7432:1998, Dierlijke mest en mestproducten - Bepaling van de gehalten aan droge stof en organische stof - Gravimetrische methode

3. Commissie Deskundigen Meststoffenwet (2018) Advies bepaling van nutriënten via NIRS.

Retrieved from: https://www.wur.nl/upload_mm/c/1/4/ff867572-9fdc-4184-af24-

35ee3cbe9cbd_1837341_CDM-

advies\%20bepaling\%20van\%20nutrienten\%20in\%20dierlijke\%20mest\%20via\%20NIRS.pdf 


\section{Appendix A1.1 Technical drawing of the flow cell}

The figure below shows a technical drawing of the flow cell with an example of a front cover with a round optic window to fit the NIRS system. In this design of the flow cell the inlet and outlet have two connections in order for the pump to provide the desired flowrate.

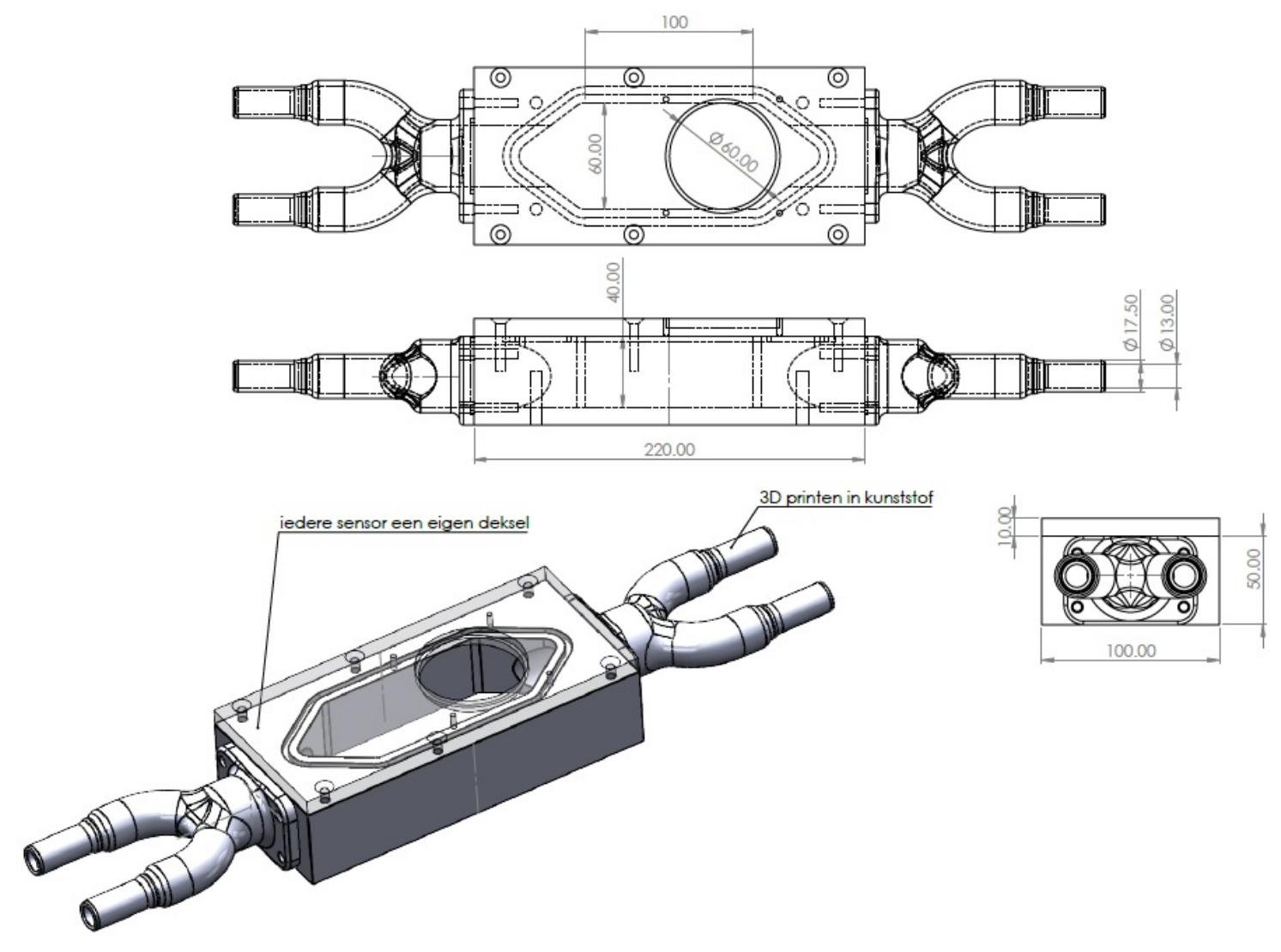

Figure A2.3 Technical drawing of the flow cell (all measures in $\mathrm{mm}$ ) 


\section{Annex 3 POP data evaluation}

Example of a report generated by the $R$ script page 1 of 3:

\section{NIRS and manure composition}

Protocol: statistical analysis of proof of principle experiment

June 10, 2021

The quality of NIRS system $\mathrm{x}$ was assessed in a proof of principle experiment with 20 manure samples. AP05 measurements show that the $N$ concentration in these samples varied from 1 to $8.9 \mathrm{~g} / \mathrm{kg}$. The $P 2 O 5$ concentration varied from 0.3 to $5.4 \mathrm{~g} / \mathrm{kg}$. See Figure 1. As shown in the Figure, a total of 0 and 0 NIR predictions were smaller or equal to zero for $N$ and $P 2 O 5$, respectively. These were not taken into account in the assessment.

Log-log regression of the NIRS values against the AP05 values is used to evaluate their agreement. Using the regression analysis the quality of the NIRS system was statically evaluated for $N$ and $P 2 O 5$ values in the range of $1-9 \mathrm{~g} / \mathrm{kg}$ and $0.25-6 \mathrm{~g} / \mathrm{kg}$, respectively. The following results are shown in Figures 2, 3, and 4

- the 95 percent 2-sided confidence interval of the systematic differences between the NIRS and AP05 $N$ values lies completely inside the region defined by the allowed deviation. The phase 1 requirement for the maximum systematic error for $N$ is met.

- the $95 / 95$ percent 2-sided tolerance interval of the relative random differences between the NIRS the values and their average (conditional on the corresponding AP05 value) lies completely inside the region given by the allowed deviation of $20 \%$. In other words, the phase 1 requirement for the maximum random error is met for $N$.

- the 95 percent 2-sided confidence interval of the systematic differences between the NIRS and AP05 P2O5 values (partly) falls outside the allowed deviation. The systematic error for $\mathrm{P} 2 \mathrm{O} 5$ needs to be further assessed.

- the $95 / 95$ percent 2-sided tolerance interval of the relative random differences between the NIRS values and their average (conditional on the corresponding AP05 value) is smaller than the allowed deviation of $30 \%$. In other words, the phase 1 requirement for the maximum random error is met for $\mathrm{P} 2 \mathrm{O} 5$.

Based on the statistical intervals it is concluded that the system does meet the phase 1 requirements for $\mathrm{N}$, and does not meet the requirements for $\mathrm{P} 2 \mathrm{O} 5$. 

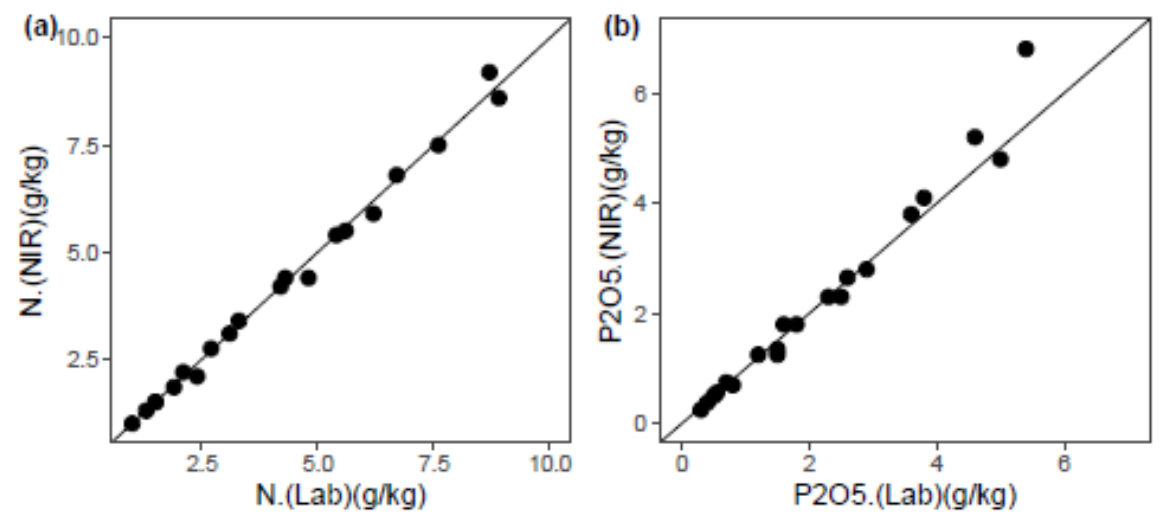

Figure 1: Correlation plot of the measured NIR values against the AP05 values for (a) $\mathrm{N}$ and (b) P2O5. The diagonal line is the line of perfect agreeement.
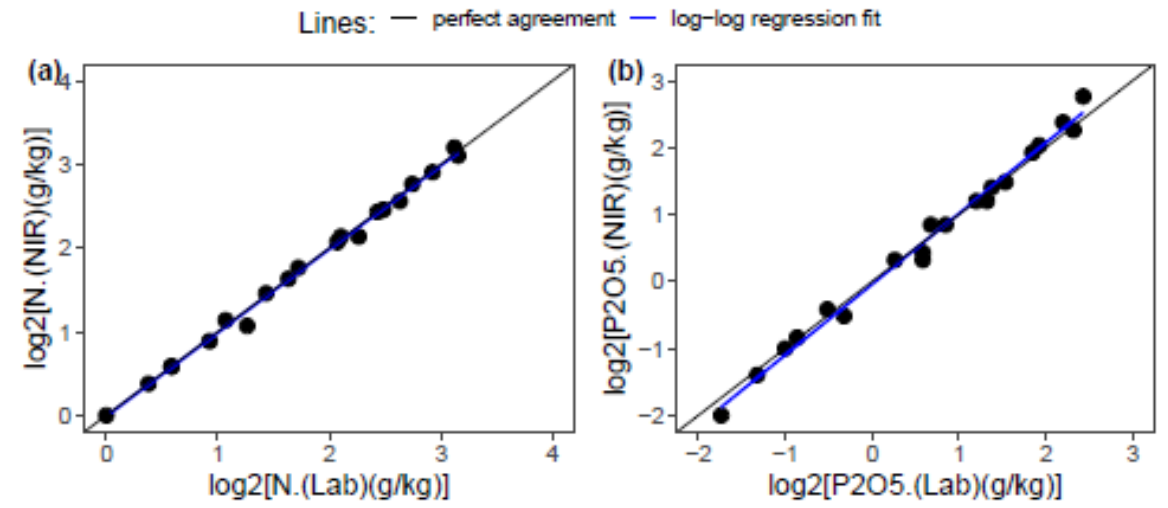

Figure 2: Plot of $\log$-log regression fit of the measured NIR values against the AP05 values for (a) $N$ and (b) P2O5 that is used to judge the quality of the NIRS system. 
(a)

- Conf. Int. - Allowed limit

(b)

- Allowed limit - Tol. Int.
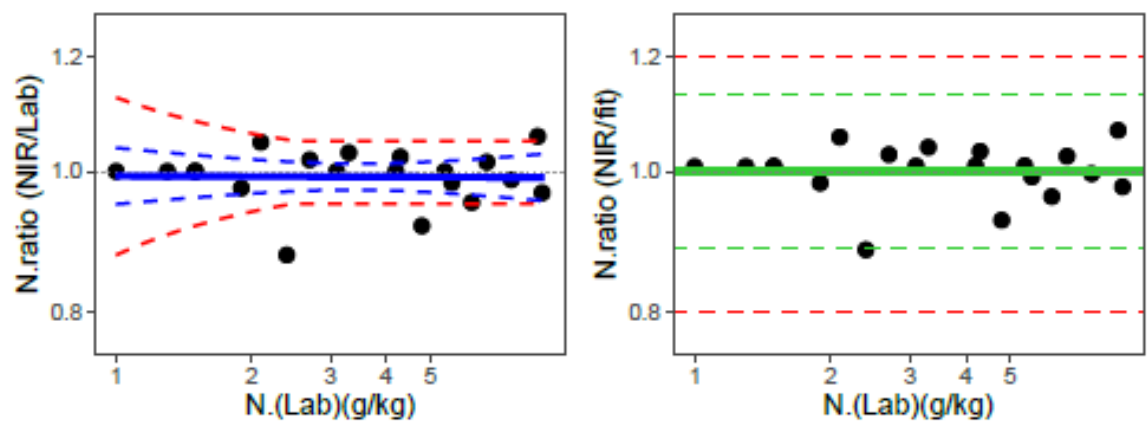

Figure 3: Results of Log-log regression of NIRS against AP05 nitrogen values. Panel (a) shows the the estimated systematic error in the form of a 2-sided confidence interval (Conf. Int.), and panel (b) shows the random error in the form of a 2-sided tolerance interval (Tol. int).

(a)

- Conf. Int. - Allowed limit

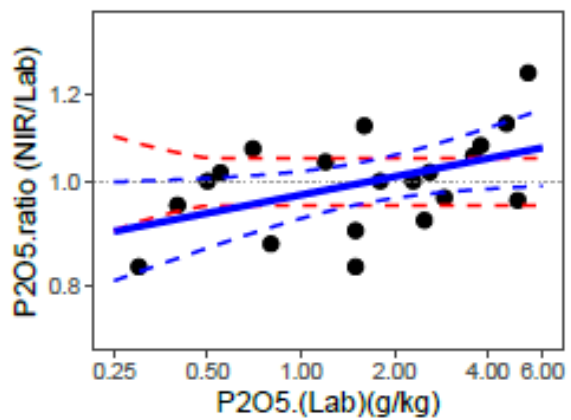

(b)

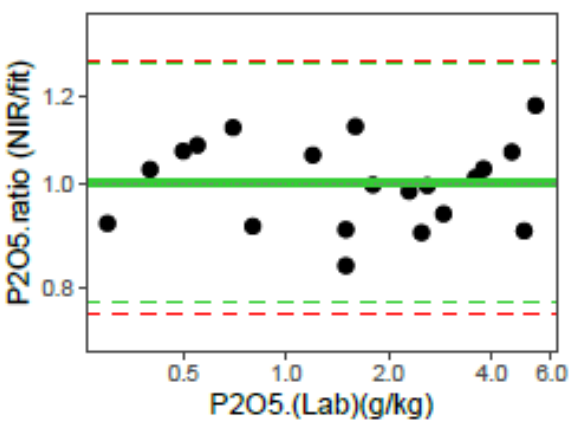

Figure 4: Results of Log-log regression of NIRS against AP05 phosphorous values. Panel (a) shows the the estimated systematic error in the form of a 2-sided confidence interval (Conf. Int.), and panel (b) shows the random error in the form of a 2-sided tolerance interval (Tol. int). 
Explanation of the POP evaluation:

\section{Proof of Principle data analysis}

This document describes how, within NIMACO, the data from a proof of principle (POP) experiment are analysed to assess the performance of a NIR system. Both the systematic and relative error of the $N$ and $\mathrm{P}_{2} \mathrm{O}_{5}$ predictions are evaluated for a prespecified concentration range. This assessment has been implemented in the software package $\mathrm{R}$ and a report is automatically generated. An example of such a report is included in the accompanying file "Protocol_example.pdf".

\section{Evaluation of the measurement results}

The POP-results are analysed using a linear modelling approach. First, all samples with predictions $\leq 0$ are excluded from the comparison (for $N$ and $P_{2} O_{5}$ separately). Next, a log2-transformation is applied to the remaining AP05 reference values and NIR predictions. Finally, a linear regression of the (transformed) NIRS values against the AP05 values is carried out. The expressions for fitting the model to the data are given on the next page (equations $1-3$ ).

An estimate of the systematic error of the NIRS system is obtained from the estimated regression line by taking the difference between the fit and AP05 value. Note that due to the log-transformation this is an estimate of the relative systematic deviation of the NIR system. The uncertainty of this estimate is quantified in the form of a two-sided confidence interval (equation 4). This interval is used first to assess the systematic error of the system: the system passes the assessment when its entire confidence interval falls completely within the maximum allowed range (expressed as maximum allowed relative deviation). Note that for low concentrations the CDM report provides absolute differences for the maximum allowed systematic error. These are therefore transformed to a maximum relative difference.

A confidence interval outside the maximum allowed range implies that the data was not informative enough to statistically show the absence of meaningful systematic deviations. This may occur even when the true systematic error of the system is small, due to the size of the random error that is allowed by CDM.*

*Therefore, for the current stage of the introduction of NIRS, where NIRS results are not yet applied for the legal determination of the nutrient content, it was decided to evaluate the systematic error by visual inspection of the results. The minimum requirement for the system to be approved this way is that the point estimate of the systematic error falls within the limits for the maximum allowed deviation. It may necessary to increase the POP sample size, to be able to statistically determine that the systematic error of NIRS falls with in the allowed limits.

The random error is evaluated based on the residuals of the fit, i.e. the differences between the NIRS predictions and the estimated regression line. A two-sided tolerance interval (equation 5 ) is used to provide limits that (with 95\% confidence) contain the random errors of at least $95 \%$ of the manure samples that would be analysed in the future by a NIRS system. A NIRS system passes the evaluation of the random errors when the entire tolerance interval falls within the maximum allowed limits for the random error. Note that due to the log-transformation this evaluation focuses on the relative random error. A typical POP experiment involves only a limited number of observations with such low concentrations that the CDM report warrants an evaluation of the absolute error. Therefore, the absolute random error cannot be evaluated statistically. However, in the analysis report figures are provided to visually assess this error.

The above-mentioned evaluation of the systematic and random errors are encapsulated in a script to enable a quick and uniform assessment of the results. In addition, all graphs of each report will be inspective visually to see if no abnormalities occur. 


\section{Assessment of an example data set}

The file "Protocol_example.pdf" contains an automatically generated report for the analysis of an example POP experiment. As mentioned in the beginning of the report, no predictions $\leq 0$ were detected and therefore all 20 measurements are used to evaluate the quality of the $\mathrm{N}$ and $\mathrm{P}_{2} \mathrm{O}_{5}$ predictions of the NIRS system. The remaining text on page 1 of the report summarizes the findings from the linear regression analysis. Accompanying Figures $1-4$ are shown on page 2 and 3 .

Figure 1 plots the NIR predictions against the AP05 reference values. The diagonal corresponds to the line of perfect agreement between AP05 values and NIRS predictions. Figure 2 shows the same plot after log2-transformation of the data. A log-log regression is used based on the assumption that the random error for the NIRS systems is approximately equal over the concentration range for $\mathrm{N}_{2} \mathrm{P}_{2} \mathrm{O}_{5}$ while the maximum allowed random error is relative to the concentration in the sample. The regression line is shown in blue. This fit is used to evaluate the systematic and random error of the system.

Figure 3 contains the results for $N$. In panel $3 a$ the systematic error of the system is evaluated. The blue solid line corresponds to the difference between the linear regression fit (from Figure 2) and the AP05 values. It is the estimate for the systematic error of the system. The confidence interval for the systematic error is indicated by the blue dotted line. The red lines correspond to the maximum allowed deviation as specified in the CDM report. It can be seen that the confidence interval falls completely inside the range of maximum deviations. Therefore, the system is approved with respect to the requirements for the systematic error.

In panel $3 \mathrm{~b}$ the relative error for the $N$ predictions is evaluated. The solid green line corresponds to the average (relative) random error, which is 1 by default. The dotted green lines corresponds to the two-sided tolerance interval. The interval is completely within the maximum allowed bounds (red lines). Therefore, $\mathrm{N}$ predictions of the system also pass the requirements for the random error.

Figure 4 displays the evaluation of $\mathrm{P}_{2} \mathrm{O}_{5}$. From panel $4 \mathrm{a}$ it is clear that based on the confidence interval it cannot be shown that the system passes the requirements for the systematic error: the interval (blue dotted lines) is outside the maximum allowed range (red). This is partly attributed to the relatively large random error of the system. However, based on visual inspect of the figure, it is clear that also the point estimate for the systematic deviation (blue solid line) is slightly outside the maximum allowed range. Therefore, the system is not approved with respect to the systematic error. The system barely passes the requirements for the random error: in Figure $4 \mathrm{~b}$ the tolerance interval (green) is just within the maximum allowed range (red).

\section{Calculations for the POP evaluation}

As an example, we focus on the evaluation of the $N$ predictions. The same procedure is used for $P_{2} O_{5}$. The following model is used to analyse the data from a POP experiment with NIRS predictions $>0$ :

$$
y_{i}=\beta_{0}+\beta_{1} x_{i}+\epsilon_{i}
$$

here, $y_{i}$ is a log2-transformed NIRS prediction for $N$ of sample $i$. The log2-transformed AP05 measurement of that sample is given by $x_{i}$ and $\epsilon_{i}$ is a normally distributed residual.

Estimates for the intercept $\beta_{0}$ and slope $\beta_{1}$ are obtained from the following two equations:

$$
\begin{gathered}
\hat{\beta}_{1}=\frac{\sum\left(x_{i}-\bar{x}\right)\left(y_{i}-\bar{y}\right)}{\sum\left(x_{i}-\bar{x}\right)^{2}} \\
\hat{\beta}_{0}=\bar{y}-\hat{\beta}_{1} \bar{x}
\end{gathered}
$$


Here, $\bar{x}$ and $\bar{y}$ correspond to the average AP05 and NIRS value, respectively. The systematic deviation of the system follows from the difference between the AP05 values and the linear regression fit $\left(\hat{y}_{h}=\right.$ $\left.\hat{\beta}_{0}+\hat{\beta}_{1} x_{h}\right)$. The confidence interval for the systematic error at AP05 concentration $x_{h}$ is given by:

$$
C I=\hat{y}_{h}-x_{h} \pm t_{0.025, n-2} \sqrt{M S E\left(\frac{1}{n}+\frac{\left(x_{h}-\bar{x}\right)^{2}}{\sum\left(x_{i}-\bar{x}\right)^{2}}\right)}
$$

with the mean squared error $\left(M S E=\sum e_{i}^{2} /(n-2)=\sum\left(y_{i}-\hat{y}_{i}\right)^{2} /(n-2), n\right.$ the number of samples with NIRS predictions $>0$, and $t_{0.025, n-2}$.the 0.025 quantile of a t-distribution with $n-2$ degrees of freedom.

For evaluation of the random error a two-sided tolerance interval for a normal distribution with a known mean (0) and unknown standard deviation is computed as follows:

$$
T I=0 \pm z_{0.975} \sqrt{M S E *(n-2) / \chi_{0.05, n-2}^{2}}
$$

Where $z_{0.975}$ corresponds to the 0.975 quantile of a standard normal distribution, and $\chi_{0.05, n-2}^{2}$ to the 0.05 quantile of a chi-squared distribution with $n-2$ degrees of freedom. 


\section{Annex 4 POA protocol}

Version: June 2021

\section{Subject and scope}

This document defines the Proof of Application (POA) for the performance assessment of NIRS systems that are used on board of tank trailers for the determination of the total nitrogen $(\mathrm{N})$ and total phosphorus content (expressed in $\mathrm{P}_{2} \mathrm{O}_{5}$ ) in animal slurry. This method is applied as a check to test whether the NIRS system on board of an individual tank trailer meets the performance requirements for the legal determination of $\mathrm{N}$ and $\mathrm{P}_{2} \mathrm{O}_{5}$ in slurry according to the Dutch Fertilizer Law in general and more in particular AP05.

\section{Normative references}

The following document is referred to in the text in such a way that some or all of their content constitutes requirements of this document.

Law uitvoeringsregeling Meststoffenwet, Annex H Accreditatieprogramma dierlijke mest; AP05, in this document referred to as AP05.

\section{Terms and definitions}

For the purposes of this document, the following term and definition apply.

\section{$3.1 \quad$ Slurry}

Mixture of animal excreta with water, feed residues and/or bedding material with a liquid constituent which allows it to be transported by pumping.

\section{$3.2 \quad$ Tank trailer}

Within this document the term tank trailer is used and refers to any vehicle that is registered by RVO for the transportation of animal slurry.

\section{Principle}

The performance of the NIRS system, installed on the specific trailer, shall be evaluated by comparing the measured $\mathrm{N}$ and $\mathrm{P}_{2} \mathrm{O}_{5}$ concentrations by the NIRS system upon loading the slurry tank trailer to those determined by laboratory analysis according to NEN standards stated in accreditation protocol AP05 on a sample that is representative for the trailer content.

For this assessment it is essential that accurate and precise results are obtained from laboratory analysis. To obtain a sample that is highly representative of the contents of the trailer, the contents shall be thoroughly mixed before the sample for laboratory analysis is taken. This shall be performed by transferring the slurry content of the tank trailer into an external tank (or test trailer). Mixing of the contents will be done by internally recirculate the slurry with the pump of the test trailer. Fifteen 
minutes of recirculating at approximately $3 \mathrm{~m}^{3} / \mathrm{min}$ has shown to be sufficient to homogenize the contents. Alternatively, an in line measuring device, using NIRS or any other suitable technique can be used, to monitor the heterogeneity of the recirculating slurry. As soon as the stage of homogeneity is reached the representative sample for laboratory analysis shall be collected using the conventional sampling device.

\section{Application purposes}

The POA protocol serves for three purposes:

1. initial approval/certification of an individual tank trailer in combination with a given NIRS system,

2. periodically quality assurance check,

3. unannounced quality inspections.

Clarification:

1. For the approval of a NIRS system on board of a specific slurry trailer 5 commercial slurry transports must be carried out with slurries from different origins. These transports shall be subjected to the POA to determine whether the NIRS system functions properly. In the time pending for results of the POA, the NIRS system of the tank trailer shall not be used for the legal determination of the nutrient content of transported slurry. When the NIRS system meets the performance requirements for all five transports, it will be certified to transport slurry for a period of $x x$ months. However, in the case one or more of the transports do not meet the performance requirements, the NIRS system should be adjusted/recalibrated before it shall be assessed again for an initial approval. For this reassessment, the entire procedure must be repeated. Any previous obtained results will be discarded. While pending the approval all commercial slurry transports performed with this tank trailer the nutrient content should be accounted for by the conventional system of sampling and laboratory analyses.

2. In order to prolong the quality certificate, the NIRS system must be re-assessed periodically by the POA. In case the NIRS system passes the POA a new certificate is provided for a given period.

3. In case of unannounced quality checks, the POA shall be used as a mid-term evaluation to determine whether the equipment meets the performance requirements.

Note: red text will be subject to decisions to be taken by the Ministry of Agriculture, based on scientific research, which has to be finalized before the start of the implementation of NIRS into practice.

\section{Specifications and requirements}

\section{$6.1 \quad$ Tank trailer}

A commercial tank trailer equipped with a NIRS system for the determination of the total $\mathrm{N}$ and $\mathrm{P}_{2} \mathrm{O}_{5}$ content in slurry. The NIRS system must be able to perform NIRS measurement during both loading and unloading of the tank trailer. In addition, after (un)loading the NIRS system should determine the $\mathrm{N}$ and $\mathrm{P}_{2} \mathrm{O}_{5}$ content and decide if the determined results are accurate enough for registration at RVO. In case the NIRS system has successfully determined the $\mathrm{N}$ and $\mathrm{P}_{2} \mathrm{O}_{5}$ content in the slurry, it shall report the results to RVO using the protocol set by RVO. Otherwise, a sample must be taken during unloading and must be handled according to the AP05 protocol. For connecting to the test trailer the tank trailer must have the opportunity to connect to 6" standard quick connectors.

\subsection{Test trailer}

A tank, possibly on board of a transport vehicle, that shall be used to homogenize the total load of slurry of a tank trailer and obtain a sample that is representative for the total trailer content.

The requirements of the test trailer are:

- The test trailer must have sufficient loading capacity to completely take over the load of all tank trailers that are used for slurry transport. 
- The test trailer must have an option to internally recirculate the content of the trailer with the pump to homogenize a slurry load.

- A sampling device must be installed on the trailer through which the slurry flows when the content of the trailer is internally recirculated with the pump. Additionally, an in-line monitor system might be installed to show any fluctuations in slurry composition during recirculation. In case a NIRS system is used for this purpose only NIRS system shall be used which have passed the Proof of Principle (POP) with positive results.

- The test trailer must be equipped with a hose that is required to connect it to any tank trailer by 6" hose and standard quick connectors.

\section{3}

\section{POA test Location}

The location where sampling of the tank trailer shall be performed. There must be enough space to safely transfer the content of the tank trailer into the test trailer. Personal safety, appropriate working conditions and environmental issues (spillage etc.) must be taken into consideration when choosing the test site.

\section{Responsibilities}

The overview given below in Table A4.1 is meant to describe the situation at the start of the implementation of NIRS on the tank trailers. Parties are invited to evaluate the roles and performance of each other on a regular base. This might lead to changes to the table given below.

Table A4.1 Responsibilities all parties involved related to the POA activities

\begin{tabular}{|c|c|}
\hline Function & Activities \\
\hline $\begin{array}{l}\text { At RVO registered } \\
\text { user of the tank } \\
\text { trailer* }\end{array}$ & $\begin{array}{l}\text { - Must ensure that NIRS system on board of tank trailer meets the performance requirements and has a } \\
\text { valid performance certificate when the trailer is used for slurry transports. } \\
\text { - Shall arrange the commercial slurry transport that can be subjected to the POA, meeting any } \\
\text { requirements set for the range of the nutrient content. } \\
\text { - Shall arrange that the tank trailer and operator of the tank trailer are present at the POA test location } \\
\text { at the agreed date and time. }\end{array}$ \\
\hline WFSR & $\begin{array}{l}\text { - Shall provide the instructions to the operator of the test trailer } \\
\text { - Shall perform wet chemical analysis on the acquired samples according to the NEN norms stated in } \\
\text { AP05 regulations. } \\
\text { - Shall retrieve the relevant load data of the tank trailer from RVO. } \\
\text { - Shall perform the statistical assessment of the measurement results. } \\
\text { - Shall provide an inspection report to RVO whether, based on the statistical assessment, the tank trailer } \\
\text { complies or does not comply with the performance requirements. }\end{array}$ \\
\hline RVO & $\begin{array}{l}\text { - Shall register the measurement results from NIRS or AP05 analysis including related transport } \\
\text { information (VDM data). } \\
\text { - Shall provide (an extension of) the exemption for the use of NIRS for the legal determination of the N } \\
\text { and } \mathrm{P}_{2} \mathrm{O}_{5} \text { content to the owner/user of the tank trailer, when the inspection report states that the tank } \\
\text { trailer does comply to the performance requirements. } \\
\text { - Shall block the registration of reported NIRS measurement results if the inspection report states that } \\
\text { the tank trailer does not comply to the performance requirements or the date of the exemption has } \\
\text { expired; unblock the system once a renewed positive evaluation of POA result(s) is reported. Other, } \\
\text { transport related data, will be recorded unaffected. } \\
\text { - Shall report the final result of the POA to the user of the tank trailer. }\end{array}$ \\
\hline NVWA & $\begin{array}{l}\text { - Shall schedule the POA with the user of the tank trailer; the date, time and location for the POA shall be } \\
\text { selected. } \\
\text { - Shall inform WFSR of the POA appointment in advance. } \\
\text { - Shall provide an operational test trailer to the POA test location. } \\
\text { - Shall arrange an operator for the test trailer who performs the POA sample collection. } \\
\text { - Shall provide supervision of the POA by a NVWA inspector. } \\
\text { - Shall clearly label the sample as a POA sample including the VDM number. } \\
\text { - Shall deliver the sample to WFSR at the same day of producing the sample, stored and transported in a } \\
\text { way the quality of the sample is unaffected. }\end{array}$ \\
\hline
\end{tabular}

\footnotetext{
* At RVO registered user of the tank trailer
} 


\section{Procedure}

The procedure below shall be slightly different in case an unannounced quality inspection is performed. In that occasion, NVWA shall select a tank trailer during its transport that shall immediately be directed to the POA test location appointed by the NVWA. As a result, the procedure continues from step 4.

1. The registered user of the tank trailer shall make an appointment with NVWA for certification of the NIRS equipment on a tank trailer. Both the date, time and location for the collection of a POA sample shall be selected suiting both parties.

2. The driver of the tank trailer shall collect a slurry load. Upon loading, the NIRS-system must determine the total $\mathrm{N}$ and $\mathrm{P}_{2} \mathrm{O}_{5}$ content of the slurry. These NIRS results shall be send to RVO directly after finishing loading, according to the protocol as defined by RVO.

3. If the NIRS system cannot determine the $\mathrm{N}$ and $\mathrm{P}_{2} \mathrm{O}_{5}$ content meeting its own standards, then. the driver reloads the truck, if needed at a different location.

4. The driver of the tank trailer shall drive the tank trailer with the collected slurry to the POA test location that has been agreed upon in step 1.

5. NVWA shall arrange that a test trailer, operator of the test trailer, and a NVWA inspector are present in time at the POA test location.

6. The driver of the tank trailer and operator of the test trailer shall position the tank and test trailer in such way that they can be connected to each other using the 6" hose of the test trailer.

7. The operator of the tank trailer and operator of the test trailer shall prepare the tank trailer and test trailer to pump the content of the tank trailer into the test trailer.

8. The operator of the tank trailer and operator of the test trailer shall collaborate to transfer the content of the tank trailer into the test trailer completely and in a safe way.

9. When the transfer is complete, the operator of the test trailer shall start the internal recirculation of the slurry with the pump (mixing).

10. The operator of the test trailer shall mix 15 minutes or any shorter as indicated by in-line monitoring device.

11. The operator of the test trailer shall collect a sample of recirculating slurry using the sampling device on board of the test trailer, discarding the first sampling portion to prevent any cross contamination from the previous test.

12. The operator of the test trailer shall stop the internal circulation of slurry.

13. The operator of the tank trailer and operator of the test trailer shall prepare the tank trailer and test trailer to pump the content of the test trailer back into the tank trailer. They shall use the $6 "$ hose of the test trailer.

14. The operator of the tank trailer and operator of the test trailer shall collaborate to transfer the content of the test trailer back into the transport trailer completely and in a safe way.

15. When the transfer is completed, the tank trailer must be disconnected from the test trailer by the driver of the tank trailer and operator of the test trailer.

16. The sample that is collected in step 10 must be labeled with the corresponding VDM number and marked so that it is clear that the sample originates from a POA inspection and therefore must be analysed individually.

17. NVWA shall ensure that the sample is transferred to WFSR on the same day under conditions that shall not result in any nutrient loss.

18. WFSR shall determine the $\mathrm{N}$ and $\mathrm{P}_{2} \mathrm{O}_{5}$ content by laboratory analysis, according to the NEN norms stated in AP05 regulations within 3 working days after receiving the sample.

19. WFSR shall acquire the loading data (e.g. NIRS-results) from RVO based on the VDM number that is recorded on the received POA sample.

20. WFSR shall perform the statistical evaluation of the NIRS and wet chemical analysis results to determine whether the NIRS-device meets the set performance requirements.

21. WFRS shall provide an inspection report of the final result of step 19 to RVO.

22. RVO shall inform the owner of the tank trailer about the results of the POA.

Point to be discussed is the leap time of each of the steps and the total process and the consequences for the parties involved in the commercial transport at the time of the POA. 
A schematic illustration of the transfer of slurry from the tank trailer to the test trailer is shown in Figure A4.1.

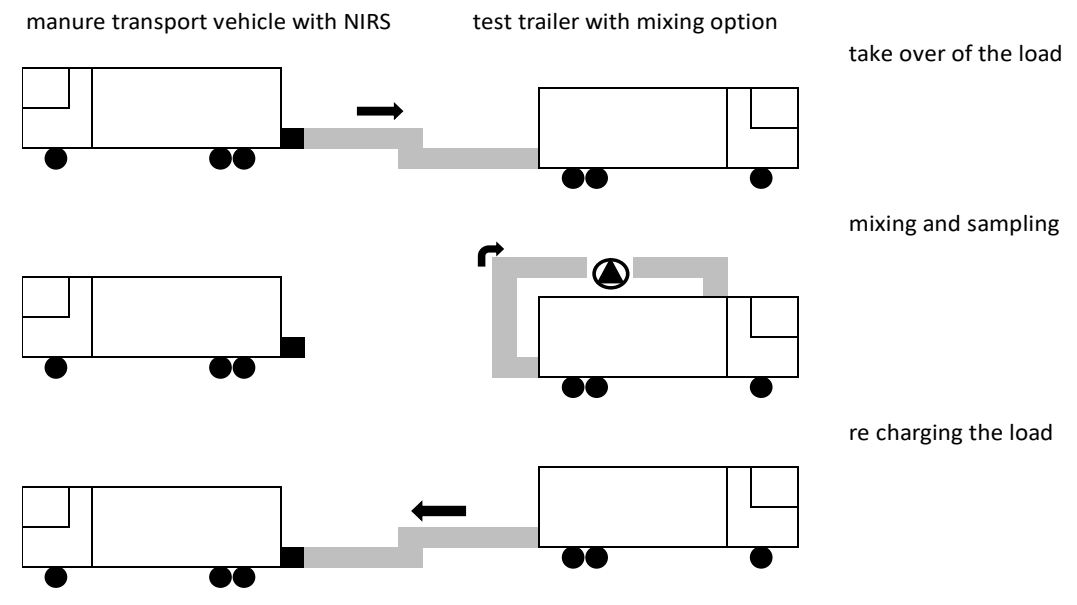

Figure A4.1 Schematic illustration of the process for collecting the representative POA sample.

\section{Evaluation of the measurement results}

The evaluation of the POA-results will be done at two levels. First of all on individual tank trailer level, which results in the conclusion if the individual tank trailer meets the performance requirements or not. In addition to that results from individual tank trailer with the same type of NIRS system on board will be evaluated. The intention of these evaluations is to identify any erroneous system as quick as possible within the limits of inspection frequency.

\subsection{Evaluation of individual tank trailers}

For the assessment of the performance of the NIRS system the measured $\mathrm{N}$ and $\mathrm{P}_{2} \mathrm{O}_{5}$ concentration by NIRS system upon loading the trailer shall be compared to the measurement results from laboratory analysis according the NEN standards stated in AP05. The performance of an individual system will be evaluated by using a Shewhart control card, as shown in Figure A4.2.

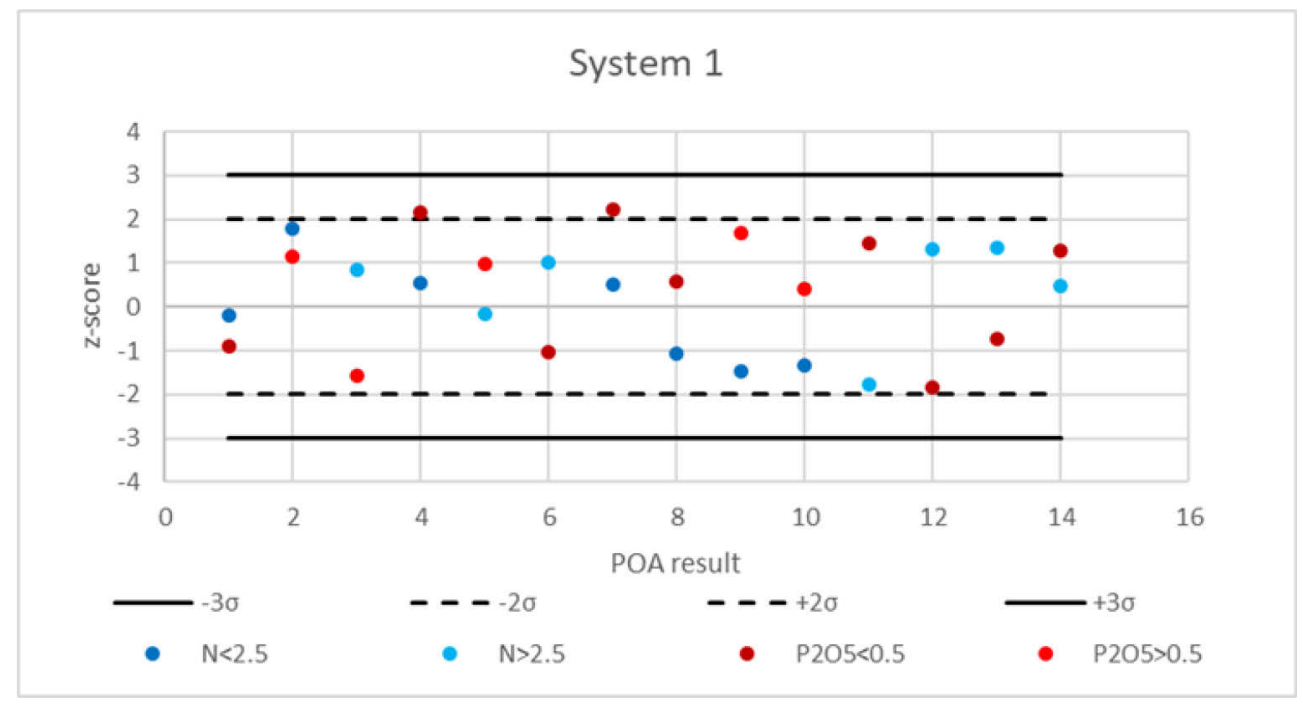

Figure A4.2 Example control chart for an individual NIRS system, showing the z-score of consecutive $P O A$ results for $\mathrm{N}$ and $\mathrm{P}_{2} \mathrm{O}_{5}$. 
The Z-score is calculated by the formula:

Z-score $=\frac{x_{N I R S}-\mu}{\sigma_{\operatorname{Max}}}$

With:

$\mathrm{X}_{\text {NIRS }}=$ NIRS result in $\mathrm{g} / \mathrm{kg}$

$\mu \quad=$ Wet chemical analysis result in $\mathrm{g} / \mathrm{kg}$

$\sigma_{\text {Max }} \quad=$ Maximal allowed random standard deviation (see Table A4.2)

Table A4.2 The maximum allowed standard deviation for the first phase (CDM report, 2018)

\begin{tabular}{lcccc} 
Element & Concentration & Systematic error & Random error & $\sigma_{\text {Max (random) }}$ \\
\cline { 2 - 5 } Nitrogen & $\leq 2,5 \mathrm{~g} / \mathrm{kg}$ & $<0,125 \mathrm{~g} / \mathrm{kg}$ & $< \pm 0,5 \mathrm{~g} / \mathrm{kg}$ & $0,25 \mathrm{~g} / \mathrm{kg}$ \\
\cline { 2 - 5 } & $>2,5 \mathrm{~g} / \mathrm{kg}$ & $<5 \%$ & $< \pm 20 \%$ & $0,1 * \mu \mathrm{g} / \mathrm{kg}$ \\
\hline Phosphorous & $\leq 0,5 \mathrm{~g} / \mathrm{kg}$ & $<0,025 \mathrm{~g} / \mathrm{kg}$ & $< \pm 0,15 \mathrm{~g} / \mathrm{kg}$ & $0,075 \mathrm{~g} / \mathrm{kg}$ \\
$\left(\mathrm{P}_{2} \mathrm{O}_{5}\right)$ & $>0,5 \mathrm{~g} / \mathrm{kg}$ & $<5 \%$ & $< \pm 30 \%$ & $0,15^{*} \mu \mathrm{g} / \mathrm{kg}$ \\
\hline
\end{tabular}

\subsection{Evaluation of the different systems}

In addition to the evaluation in 9.1 the performance of all NIRS systems from a given type will be evaluated in order to detect any systematic deviation. The results from individual tank trailers with the same type of NIRS system on board will be combined to evaluate if the differences in the average results from one system to the wet chemical analysis results remain within the limits given by the measuring technique. The latter is similar to the quality assurance program currently applied to the commercial AP05 laboratories (see AP05).

\section{References}

1. Commissie Deskundigen Meststoffenwet (2018) Advies bepaling van nutriënten via NIRS. Retrieved from: https://www.wur.nl/upload_mm/c/1/4/ff867572-9fdc-4184-af2435ee3cbe9cbd_1837341_CDMadvies\%20bepaling\%20van\%20nutrienten\%20in\%20dierlijke\%20mest\%20via\%20NIRS.pdf 
Wageningen Food Safety Research

P.O. Box 230

6700 AE Wageningen

The Netherlands

T +31 (0)317480256

www.wur.eu/food-safety-research

WFSR report 2021.012
The mission of Wageningen University \& Research is "To explore the potential of nature to improve the quality of life". Under the banner Wageningen University \& Research, Wageningen University and the specialised research institutes of the Wageningen Research Foundation have joined forces in contributing to finding solutions to important questions in the domain of healthy food and living environment. With its roughly 30 branches, 6,800 employees (6,000 fte) and 12,900 students, Wageningen University \& Research is one of the leading organisations in its domain. The unique Wageningen approach lies in its integrated approach to issues and the collaboration between different disciplines. 



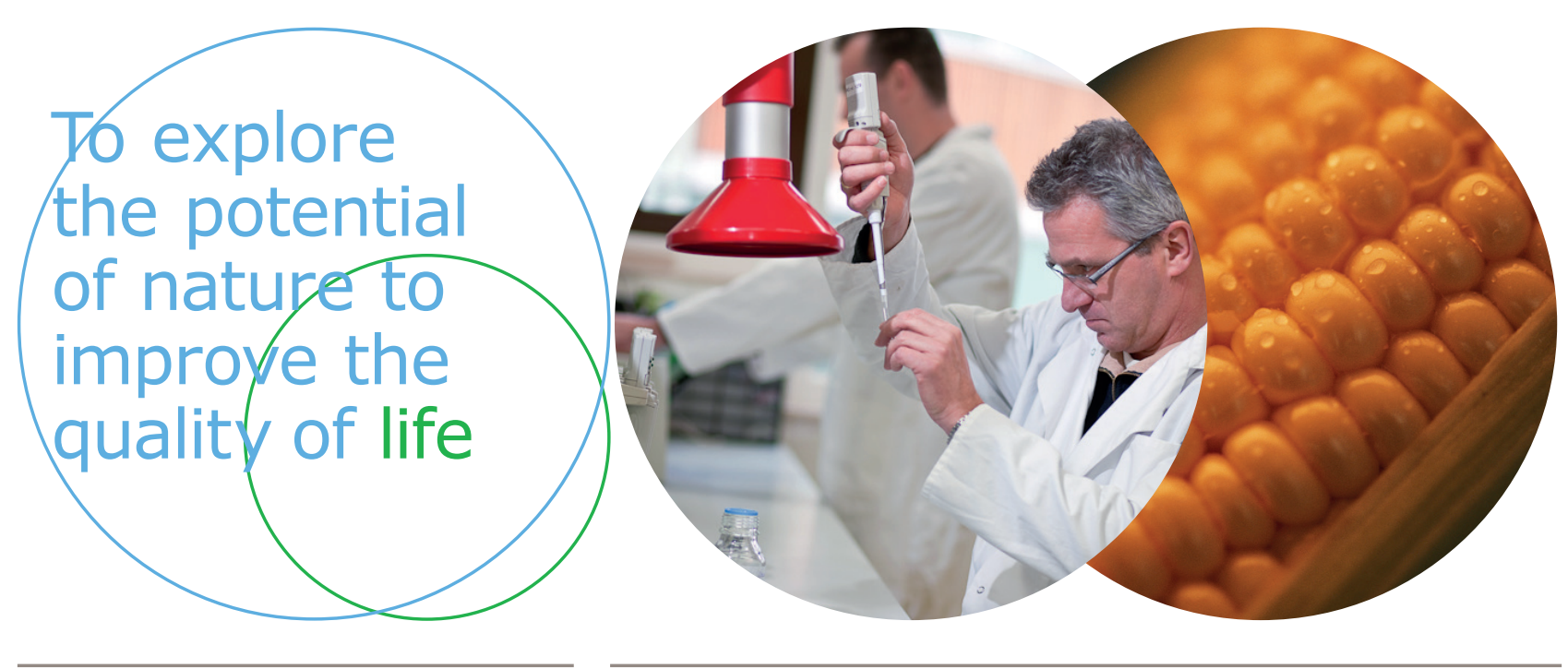

Wageningen Food Safety Research P.O. Box 230

6700 AE Wageningen

The Netherlands

T +31 (0)317480256

www.wur.eu/food-safety-research

WFSR report 2021.012
The mission of Wageningen University \& Research is "To explore the potential of nature to improve the quality of life". Under the banner Wageningen University \& Research, Wageningen University and the specialised research institutes of the Wageningen Research Foundation have joined forces in contributing to finding solutions to important questions in the domain of healthy food and living environment. With its roughly 30 branches, 6,800 employees (6,000 fte) and 12,900 students, Wageningen University \& Research is one of the leading organisations in its domain. The unique Wageningen approach lies in its integrated approach to issues and the collaboration between different disciplines. 